\title{
Synthesizing TSCA and REACH: Practical Principles for Chemical Regulation Reform
}

\author{
John S. Applegate*
}

The European Union's newly enacted comprehensive regulation for industrial chemicals, known as REACH, draws heavily on three decades of experience in the United States under the Toxic Substances Control Act. Much of that experience has been negative-TSCA is widely regarded as a disappointment among U.S. environmental laws-and so REACH deliberately reverses many of the legislative choices that Congress made in TSCA. REACH also takes advantage of important new regulatory devices that were not available to the framers of TSCA thirty years ago. The passage of REACH has sparked renewed interest in reforming TSCA, and the reformers will undoubtedly look to REACH for ideas. This Article contends that, while many aspects of REACH can fairly be understood as the Anti-TSCA, on closer examination, REACH follows many of TSCA's fundamental approaches to chemical regulation. These similarities offer a unique opportunity to develop a synthesis of the two regulatory regimes, which could form the practical basis for updating TSCA. While reform based on a synthesis of TSCA and REACH would be evolutionary rather than revolutionary, it could nevertheless greatly improve chemical regulation in the United States. The basis for such reform is likely to remain a risk-based, chemical-based, and cost-sensitive system. Nevertheless, a stronger commitment to progressive improvement could be obtained by a consistent effort to eliminate the most dangerous chemicals, the development of safety plans for the remainder, and consistent incentives to find

Copyright $(2008$ by the Regents of the University of California.

* Executive Associate Dean for Academic Affairs and Walter W. Foskett Professor of Law, Indiana University Maurer School of Law-Bloomington. I am grateful to Bernard Goldstein and the European Union Center of Excellence and Graduate School of Public Health of the University of Pittsburgh for the invitation to participate in an excellent conference on $\mathrm{REACH}$; to the participants in the conference, whose contributions greatly improved my understanding of REACH; to $E$. Donald Elliott for the opportunity to present this Article at his regulation seminar at Georgetown University Law Center; to him, Gail Charnley, and Ernest Rosenberg for many helpful comments; and to Wendy Wagner for her collaboration on the TSCA chapter of CPR for the Environment (http://www.progressivereform.org), where some of these ideas first appeared. 
safer substitutes. Chemical regulation should be more truly precautionary by relying primarily on available information with less demand for information that does not yet exist; regulators must be able to act in advance of full certainty; and, in contrast to the present procedural complexity of TSCA, the regulatory system should be simplified and include heavy reliance on providing information to the public. The Article concludes with a brief discussion of the global impact of national regulatory systems like REACH.

Introduction

I. Thesis: TSCA and Its Discontents............................................ 724

A. The Congressional Response to Toxic Substances...................... 724

1. Chemicals as Chemicals ................................................. 725

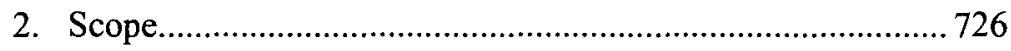

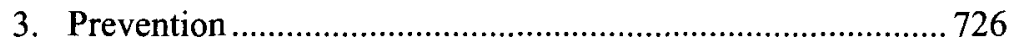

4. Probabilistic Risk ............................................................ 728

5. Information and Filling the Data Gap ................................. 729

6. Support for the Chemical Industry...................................... 730

7. New and Existing Chemicals ............................................... 731

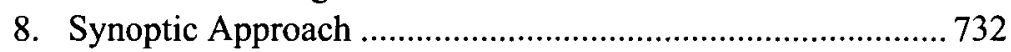

9. Procedural Complexity ....................................................... 733

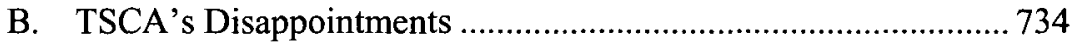

1. Information Gathering ........................................................ 734

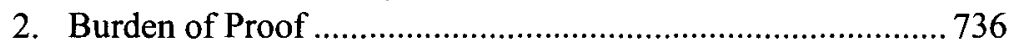

3. Procedural Hurdles ............................................................ 737

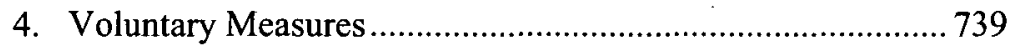

II. Antithesis: REACH and its Promise................................................ 741

A. The EU Response to TSCA …................................................. 741

B. REACH as the Anti-TSCA ................................................... 743

1. Existing Uses ................................................................. 743

2. Generation of New Information......................................... 744

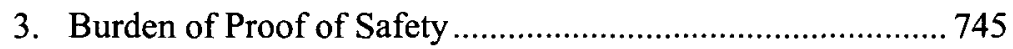

C. New Ideas in REACH .......................................................... 747

1. The Precautionary Principle............................................. 747

2. Substitution of Safer Alternatives........................................ 749

3. Transparency and the Right to Know ................................. 750

4. Reduced Animal Testing ............................................... 751

III. Synthesis: Shared Ideas and TSCA Reform .................................... 752

A. Plus ça change, plus c'est la même chose .................................753

1. Twin Goals of Environmental and Economic Health ........... 753

2. Chemicals As Chemicals ................................................... 754

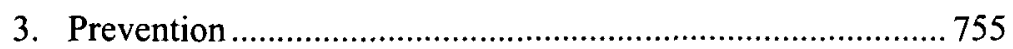

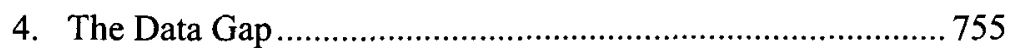

5. Risk, Proportionality, and Cost......................................... 756

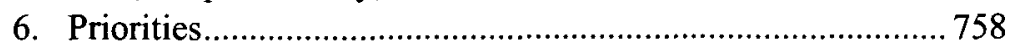




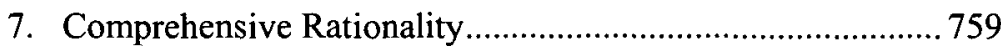

B. Practical Principles for TSCA Reform...................................... 761

1. Prevention and Proportion ............................................... 761

2. Progressive Improvement ............................................... 762

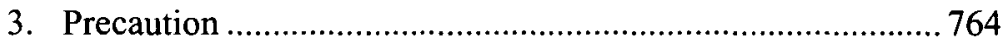

4. Transparency and Simplicity ............................................. 766

Conclusion: Chemical Regulation and Globalization ................................. 767

\section{INTRODUCTION}

At the end of 2006, the European Union (EU) adopted a comprehensive system for the regulation of industrial chemicals throughout Europe, which is known by its acronym, REACH, for Registration, Evaluation, and Authorization of Chemicals. The immediate impetus for REACH was to replace the complicated and confusing system of over forty different directives and regulations with a single (if complex) regulatory regime. However, the European Commission ("the Commission") also saw an opportunity to develop a regulatory program that would address substantive deficits in the existing regulatory structure. The Commission's White Paper: Strategy for a Future Chemicals Policy, the policy foundation for REACH, published in 2001, focused particularly on the "data gap" for toxic chemicals, the requirement that government prove the need for regulation, the relatively lax standards applied to existing (as opposed to new) chemicals, and animal testing. ${ }^{1}$

In assessing the existing regulation of chemicals, the Commission had before it the United States' experience with the Toxic Substances Control Act (TSCA). Enacted exactly three decades earlier, in 1976, TSCA is widely regarded as a serious under-performer among U.S. environmental laws, despite having itself been based on a thoughtful white paper, Toxic Substances, written by the U.S. Council on Environmental Quality (CEQ) five years earlier ${ }^{2}$ to accompany the original legislative proposal. However, a highly compromised final statutory text, hostile judicial interpretation, and often timid implementation have undermined TSCA to the point that the Environmental Protection Agency (EPA) now relies primarily on informal, voluntary measures to regulate industrial chemicals, rather than risk the total evisceration of the statute by the courts. With this as background, the Commission's White Paper can be read as an extended critique of TSCA, and REACH as the legislative product of that critique.

1. European Comm'n, Commission White Paper: Strategy for a Future Chemicals Policy, 6, COM (2001) 88 final (Feb. 2, 2001) [hereinafter Commission White Paper]. These themes are echoed in the Commission's Explanatory Memorandum that accompanied the formal legislative proposal in 2003. European Comm'n, Commission Proposal for a Regulation of the European Parliament and of the Council Concerning the Registration, Evaluation, Authorisation, and Restriction of Chemicals (REACH), 6-55, COM (2003) 644 final (Oct. 29, 2003) [hereinafter Commission Proposal].

2. U.S. COUNCIL ON ENVTL. QUALITY, TOXIC SUBSTANCES (1971) [hereinafter US CEQ]. 
TSCA and REACH are thus a matched pair-Toxic Substances and TSCA in 1971 and 1976, respectively, and the Commission's White Paper and REACH in 2001 and 2006, respectively-and it can be helpful to compare them in the Hegelian framework of thesis and antithesis. ${ }^{3}$ TSCA, the thesis, established a comprehensive approach to chemical regulation. The failures of the TSCA approach led to its negation in REACH, TSCA's apparent antithesis. A synthesis, the outcome of the Hegelian dialectic, would be achieved by reconciling the contradictions between TSCA and REACH, and recognizing in them commonalities that serve as the basis for a new approach. The synthesis would, ideally, be realized in the overdue reform of TSCA in the United States. While the thesis-antithesis-synthesis structure can be overdrawn, because TSCA and REACH do in fact share important features, the dialectic provides a useful framing device for analyzing these important, and importantly different, regulatory regimes for industrial chemicals. With or without TSCA reform, the two regulatory schemes will guide the global chemical industry and regulate chemical risks for the foreseeable future.

\section{THESIS: TSCA AND ITS DISCONTENTS}

\section{A. The Congressional Response to Toxic Substances}

Toxic Substances identified a wide range of problems with the thenexisting system (or lack thereof) for the control of toxic hazards of industrial chemicals, and Congress crafted TSCA to give EPA comprehensive authority to control these hazards. In Toxic Substances, CEQ was particularly concerned about the gaps left by the media-based pollution statutes-gaps such as loss of the opportunity to prevent pollution in the first place and transfer of pollution from one media to another-and the lack of adequate information concerning the effects of such substances. ${ }^{4}$ The authors of Toxic Substances were particularly concerned that the existing media-based pollution laws (mainly, air and water) failed to account either for individuals' total exposure to chemicals or for chemical pollution that shifts among media. Toxic Substances also highlighted the dearth of information about the effects of those exposures, even if they were known and regulated. ${ }^{5}$

Against this backdrop, Congress originally conceived TSCA as a farsighted and potentially far-reaching statute. Toxic Substances identified the lack of adequate toxicological information and the multi-media nature of chemical pollution as the key challenges for chemicals regulation, and Congress

3. The story of TSCA and REACH is told from a similar perspective in MARK SCHAPIRO, EXPOSED: THE TOXIC CHEMISTRY OF EVERYDAY PRODUCTS AND WHAT'S AT STAKE FOR AMERICAN POWER 131-56 (2007).

4. US CEQ, supra note 2, at 20-22.

5. Id. at 6-14, 22. 
expressly incorporates these concerns into TSCA's preamble. ${ }^{6}$ TSCA's orderly structure was intended to be capable of covering all phases of chemical production and use in order to fill gaps left by other statutes, and to offer a range of techniques for informed chemical regulation. The adoption of these objectives entailed several crucial legislative choices in the regulatory structure established by TSCA.

\section{Chemicals as Chemicals}

Toxic Substances devoted considerable space to explaining the many reasons to focus "on the pollutant rather than on the particular medium being polluted,"7 and these views are repeated in the legislative history of TSCA. ${ }^{8}$ First, regulating chemicals as such enables preventive regulation, before people or the environment are exposed to them. Second, regulating chemicals as such has the capacity to control them at their source, which is universally recognized to be the most efficient and effective point of control. This is especially the case for pollutants that persist in the environment for a long time and thus disperse widely and even globally (DDT, for instance). Persistent chemicals often bioaccumulate (DDT again), resulting in higher doses to affected populations. Third, regulation of chemicals can encourage the development of a true cradle-to-grave (production-to-disposal) management approach. Some chemicals, like pesticides, are intentionally introduced into the environment. They are thus a major vector for introducing new hazards to human health and the environment, and excellent candidates for a thorough approach to risks. ${ }^{9}$ Fourth, reliance on the basic media-based pollution statutes (for air emissions, water effluents, and land disposal ${ }^{10}$ ) creates a serious danger that regulated entities will merely shift waste products between media. One might avoid land disposal by incinerating, for example, or send water pollutants to a landfill. While it is possible to regulate in triplicate, so to speak, it is a highly complex undertaking because standards and techniques for one medium frequently do not translate to another. ${ }^{11}$ Finally, there are significant benefits to the regulated industry in the chemical-based approach. Regulation in triplicate is a compliance officer's nightmare, especially when regulatory programs are delegated to the states (as the media programs are in the United States), so that multiple versions of each are applicable to different parts of the same enterprise.

6. Toxic Substances Control Act (TSCA) § 2, 15 U.S.C. § 2601 (2006).

7. US CEQ, supra note 2 , at $\mathrm{v}$-vi.

8. S. REP. No. 94-698, at 1-2 (1976).

9. Donald T. Hornstein, Lessons from Federal Pesticide Regulation on the Paradigms and Politics of Environmental Law Reform, 10 YALE J. ON REG. 369, 393-400 (1993).

10. For these purposes, the workplace might be considered a fourth separate medium, distinct from the ambient air, water, and land environments.

11. US CEQ, supra note 2, at 20-21. 
By regulating chemicals per se, TSCA was supposed to avoid these gaps, or fill them when they appear, as well as to regulate more efficiently and effectively. In addition, the multi-media approach serves TSCA's preventive goals: the "obvious limitation of controls over effluents is that they . . . do not provide for obtaining information on potential pollutants before widespread damage has occurred."12

\section{Scope}

To implement these goals, Congress's first step was to identify the chemicals to regulate. Since the problems described in Toxic Substances were common to essentially all industrial chemicals, the universe of TSCA's coverage is very broad, with only limited exceptions for chemicals that are regulated by other statutes, such as the Federal Food, Drug, and Cosmetic Act and the Federal Insecticide, Fungicide, and Rodenticide Act (FIFRA). ${ }^{13}$ In keeping with the goal of comprehensiveness, section 6 of TSCA provides broad regulatory authority, giving EPA the ability to control the life-cycle of chemicals from manufacture through disposal (the latter has been rarely used, except for PCBs, which were a special concern of the statute) and export. TSCA also provides authority for addressing potential risks (by requiring additional testing) and imminent hazards (by taking relatively swift action). As to mode of regulation, EPA is authorized to regulate manufacturing processes, warnings, concentrations, labels, uses, recordkeeping, and downstream notification-pretty much anything that would reduce risk.

\section{Prevention}

CEQ intended TSCA's fundamental attribute to be prevention. CEQ was explicit that the chemical regulation system should not merely respond to harms that had already occurred:

Our awareness of environmental threats, our ability to screen and test substances for adverse effects, and our capabilities for monitoring and predicting, although inadequate, are now sufficiently developed that we need no longer remain in a purely reactive posture with respect to chemical hazards. We need no longer be limited to repairing damage after it has been done; nor should we allow the general population to be used as a laboratory for discovering adverse health effects. ${ }^{14}$

To accomplish the shift to a preventative regulatory scheme, Toxic Substances advocated a system of substantive standards to be met by new chemicals, ${ }^{15}$

12. Id. at 20 .

13. See Food, Drug, and Cosmetic Act, 21 U.S.C. 301-309 (2006); Federal Insecticide, Fungicide, and Rodenticide Act (FIFRA), 7 U.S.C. 136-136y (2006).

14. Id. at 21 .

15. Id. at 22 . 
implicitly through some kind of licensing mechanism of the kind that exists for prescription drugs and pesticides.

The emphasis on prevention-based regulation in Toxir. Substances stands in contrast to the failure of the tort system to prevent the harmful effects of toxic chemicals. The tort system only responds to harms that have already occurred and does not prohibit harm-causing activities; rather, it seeks to remedy past harms with money damages. As a compensatory system, this approach is flawed because much harm (death, dismemberment, pain) cannot be fully rectified by payment, and the failure to forbid the infliction of physical harm in advance violates a sense of human dignity and autonomy. More importantly, from a regulatory point of view, tort law is also supposed to act as a deterrent to future harm-causing activity, because subsequent risk-creators will realize that they will have to pay for the harm they cause. However, riskcreators will refrain from certain activities only to the extent that the cost of preventing the harm is less than the cost of the harm. ${ }^{16}$ That is, the level of protection is set by the individual tortfeasors' assessment of the comparative costs of prevention and liability, rather than by a collective public judgment of an acceptable level of harm. TSCA's adoption of a system based on risk rather than harm represent such a collective judgment. ${ }^{17}$

Congress sought to create the kind of preventative scheme in TSCA that was advocated in Toxic Substances by creating requirements of manufacturers to be met before a chemical is brought to market. The Senate drafting committee reported,

The most effective and efficient time to prevent unreasonable risks to public health or the environment is prior to first manufacture. It is at this point that the costs of regulation in terms of human suffering, jobs lost, wasted capital expenditures, and other costs are lowest. Frequently, it is far more painful to take regulatory action after all of these costs have been incurred. ${ }^{18}$

In furtherance of this objective, TSCA includes the pre-manufacture notice $(\mathrm{PMN})$ procedure, which requires a chemical manufacturer to notify EPA of its intention to offer a new chemical for sale for stated purposes and to provide identity and risk information in its possession at the time. ${ }^{19}$ EPA is given a limited time to object before the new substance (or significant new use of an existing substance) is released to the market and the environment. While this is

16. This assumes that the tort system accurately assesses the costs. For toxic substances, where causation is often very difficult to prove because of the nature of toxic injury, the tort system can be expected to understate the costs. Wendy E. Wagner, Choosing Ignorance in the Manufacture of Toxic Products, 82 CORNELL L. REV. 773, 774-76, 784-85 (1997) [hereinafter Choosing Ignorance].

17. See Guido Calabresi, The Costs of ACCIDENTS: A LEGAl AND ECONOMIC ANALYSIS, 95107 (1970).

18. S. REP. No. 94-698, at 5 (1976).

19. TSCA $\S 5,15$ U.S.C. $\S 2604$ (2006). 
more a procedural than a substantive hurdle for new chemicals-as discussed later-it clearly reflects the preventive goal of Toxic Substances.

\section{Probabilistic Risk}

Congress had choices among regulatory mechanisms for implementing TSCA's preventive goal. ${ }^{20}$ One strategy would have been to simply classify chemicals as hazardous and ban them, or as safe and allow their sale. A prominent example of this approach can be found in the 1958 Delaney Clause in the Federal Food, Drug, and Cosmetic Act, which simply bans as additives in foods or drugs any substance that "is found to induce cancer when ingested by man or animal."21 The restrictions of the Delaney Clause are based solely on the carcinogenic property of the chemical; the chemical's potency and the degree of exposure are irrelevant to the statutory analysis. It relies on a simple, bi-modal (safe-unsafe) proposition: if the chemical is a carcinogen, then it must be banned. Alternatively, risk can be understood as a probability or a matter of degree. This alternative, probability-of-harm approach conceives of risk as the product of the severity of the hazard to be avoided and the likelihood or probability of harm.

The full implications of the bi-modal Delaney Clause strategy may not have been fully appreciated when it was enacted, and regulators and commentators soon began to distinguish between risk in the sense of hazard, which is the simple existence of danger and as such either exists or does not, and risk in the sense of probability, which creates a spectrum of likelihood from zero (impossible) to one hundred percent (certainty). ${ }^{22}$ Probability allowed subsequent regulatory regimes to avoid the all-or-nothing consequences of the Delaney Clause approach. Instead, more recent systems tend to view chemical hazards as incrementally scalable based on their toxic potency and the amount of exposure to the chemical. This is especially useful when one is focusing on a chemical hazard like cancer, which generally does not have a step-wise progression of doses with distinctive effects, but rather presents a scaled likelihood of occurrence.

In TSCA, Congress plainly chose the probabilistic meaning of risk, ${ }^{23}$ and it did not reject all risk, but only unreasonable risk. ${ }^{24}$ The "unreasonable risk"

20. See John S. Applegate, Bridging the Data Gap: Balancing the Supply and Demand for Chemical Information, 86 TEX. L. REv. 1365, 1366-77 (2008) [hereinafter Bridging the Data Gap]; John S. Applegate, Introduction: Environmental Risk: Defining the Problem and Disciplining the Response, in THE INTERNATIONAL LIBRARY OF ESSAYS IN ENVIRONMENTAL LAW: ENVIRONMENTAL RISK xiv-xix (Ashgate ed., 2004) [hereinafter Introduction]; Elizabeth Fisher, Risk and Environmental Law: A Beginner's Guide, in ENVIRONMENTAL LAW FOR SUSTAINABILITY 97-125 (Benjamin J. Richardson \& Stepan Wood eds., 2006) (for descriptions of the rise of risk-based regulation).

21. Federal Food, Drug and Cosmetics Act $\S 409,21$ U.S.C. $\S 348$ (c)(3)(A) (1958).

22. See Applegate, Bridging the Data Gap, supra note 20, at 1366-67.

23. H.R. REP. NO. 94-1341, at 14 (1976). 
standard in section 6 (containing TSCA's basic regulatory authorities) is the touchstone of TSCA's substantive provisions, and virtually all of TSCA's regulatory provisions, such as testing requirements and imminent hazards, are variations on that theme. ${ }^{25}$ Probabilistic risk serves TSCA's objectives well in several respects. Risk, of course, denotes the potential for harm, and it supports a regulatory system where the goal is avoidance of harm to human health and the environment, rather than after-the-fact compensation. ${ }^{26}$ Risk permits preventive action. "Unreasonable risk" is undefined in the statute, but the legislative history and subsequent judicial interpretation consistently interpret it as a greater-than-zero level that is determined by reference to health, benefits, and costs. Further, the probabilistic meaning of risk meshes well with the scalable regulatory authority given to EPA in TSCA. More serious risks can be addressed with more severe restrictions, and protection from particular kinds of risks can be accomplished with targeted regulatory responses.

\section{Information and Filling the Data Gap}

Probabilistic risk-based regulation must, almost by definition, be sciencebased regulation. The whole enterprise of determining a level of risk demands a high degree of scientific knowledge because the relevant probabilities can only be ascertained through detailed understanding of the toxic properties of chemicals and their degree of exposure to humans and the environment. If the goal is to quantify the risk ${ }^{27}$-which is the logical consequence of thinking about probabilities - the data needs are intensified. ${ }^{28}$ CEQ's report was prescient in identifying lack of information about chemicals as a major challenge for effective chemical regulation, ${ }^{29}$ and Congress was persuaded. ${ }^{30}$ Whether or not Congress fully foresaw a science-based, information-intensive regulatory regime, its repeated calls for more data strongly suggest it did.

In deciding on this approach, Congress consciously drafted TSCA to push manufacturers and the EPA to fill the "data gap" identified in Toxic Substances.

24. Id. at 15. See also John S. Applegate, The Perils of Unreasonable Risk: Information, Regulatory Policy, and Toxic Substances Control, 91 COLUM. L. REV. 261, 273-277 (1994) [hereinafter Perils].

25. For example, the basic regulatory actions are authorized for chemicals that "present an unreasonable risk," TSCA $\S 6,15$ U.S.C. $\$ 2605$ (2006), information may be required about chemicals that "may present an unreasonable risk," $\S 4$, and urgent action may be taken against an "imminent and unreasonable risk, $\S 7(\mathrm{f})$.

26. See H.R. REP. No. 94-1341, at 1-4 (1976); RoBERT A. SHAPIRO \& RobERT L. GLickSMAN, RISK REgUlations AT RISK: RESTORING A PRAGMATIC APPROACH 1-2 (2003). See generally Applegate, Bridging the Data Gap, supra note 20.

27. Moreover, quantification of risk became a de facto goal in all toxics areas after the "Benzene" case in the U.S. Supreme Court. See Indus. Union Dep't v. Am. Petroleum Inst., 448 U.S. 607 (1980).

28. See Applegate, Perils, supra note 24, at 285.

29. US CEQ, supra note 2, at iv, 9-10.

30. "This vast volume of chemicals have, for the most part, been released into the environment with little or no knowledge of their long-term health or environmental effects." H.R. REP. No. 94-1341, at 3 (1976). 
The substantively demanding and procedurally complex provisions of TSCA require substantial information for making regulatory decisions. A regulatory scheme that took a less nuanced approach to risk or mandated safeguards across the board would have allowed EPA to act, even in the absence of information on the effects of particular chemicals. For example, technology-based standards-already familiar from the Clean Water $\mathrm{Act}^{31}$-would have demanded relatively little chemical information, while risk-based standards tend to require a great deal. Risk-based TSCA requires EPA to consider a wide array of information, including alternatives, and it backs this up by requiring specific findings and permitting aggressive judicial review. ${ }^{32}$

Another of Congress' "basic policy objectives" in TSCA was to place the responsibility for generating this information on manufacturers: ${ }^{33}$

It is the policy of the United States that . . adequate data should be developed with respect to the effect of chemical substances and mixtures on health and the environment and that the development of such data should be the responsibility of those who manufacture and those who process such chemical substances and mixtures . . . ${ }^{34}$

It includes a menu of data-gathering provisions to effectuate this goal. While EPA is authorized to conduct its own research, ${ }^{35}$ most of the data-gathering techniques envision production of the information by the regulated entities. New chemicals, in particular, are subject to pre-manufacture notification, which gives EPA an opportunity to examine existing data on new chemicals or new uses of existing chemicals and to object if it finds an unreasonable risk or believes that additional data are needed..$^{36}$ For existing chemicals, a wider range of techniques was provided: "test rules" that require manufacturers to generate risk data; significant new use rules (SNURs) that trigger a further PMN process for existing chemicals; data on manufacturing and processing; updates of the Inventory of Chemical Substances; and the reporting of adverse health effects, published and unpublished health and safety studies, and "substantial risks."37

\section{Support for the Chemical Industry}

The choice of "unreasonable risk" as a standard implicitly requires the balancing of many considerations to determine what constitutes "unreasonable." In part, this stems from the scalable (as opposed to bi-modal)

31. See Wendy E. Wagner, The Triumph of Technology-Based Standards, 2000 U. ILL. L. REV. 83, 88-107 (2000).

32. See Applegate, Bridging the Data Gap, supra note 20, at 1386-86; John S. Applegate \& Robert Fischman, Missing Information: The Scientific Data Gap in Conservation and Chemical Regulation, Forward 83 IND. L.J. 399, 402-04 (2008).

33. S. REP. NO. 94-698, at 17 (1976).

34. TSCA $\S 2(b)(1), 15$ U.S.C. $\S 2601$ (b)(1) (2006).

35. Id. $\$ 10$.

36. Id. $\S 5$.

37. Id. $\S \S 4,5,8$. 
nature of the probabilistic approach to risk adopted by TSCA. It also stems from a desire to protect, if not promote, useful economic activity. While the authors of Toxic Substances focused on health and environmental effects, Congress was also concerned about the impact of regulation on the important U.S. chemical industry:

It is the intent of Congress that the Administrator shall carry out this chapter in a reasonable and prudent manner, and that the Administrator shall consider the environmental, economic, and social impact of any action the Administrator takes or proposes to take under this chapter. ${ }^{38}$

The central substantive standard for chemicals regulation-unreasonable riskfurthers these dual objectives. While Congress expressly declined to define "unreasonable" in quantitative (risk levels or cost-benefit ratio) or comparative terms, it did make clear that "unreasonable" was to be determined by a range of factors, including direct and indirect costs:

In general, a determination that a risk associated with a chemical substance or mixture is unreasonable involves balancing the probability that harm will occur and the magnitude and severity of that harm against the effect of proposed regulatory action on the availability to society of the benefits of the substance or mixture, taking into account the availability of substitutes for the substance or mixture which do not require regulation, and other adverse effects which such proposed action may have on society. ${ }^{39}$

Congress, in other words, attempted to strike a balance between protective regulation and protecting an important segment of the U.S. economy. This is not an irrational or unexpected approach, but it has important consequences for the substantive and procedural burdens that the chemical industry was expected to bear.

\section{New and Existing Chemicals}

In crafting TSCA, Congress also faced the decision whether to distinguish between established uses and novel products entering the market. The old-new distinction is a long-standing conundrum in environmental regulation, because new regulatory regimes are almost always grafted onto existing technologies. It is generally cheaper to regulate only new entrants, since they can more readily

38. Id. $\S 2(\mathrm{c})$. In addition, section 2(b)(3) states that "authority over chemical substances and mixtures should be exercised in such a manner as not to impede unduly or create unnecessary economic barriers to technological innovation while fulfilling the primary purpose of this Act to assure that such innovation and commerce in such chemical substances and mixtures do not present an unreasonable risk of injury to health or the environment."

39. H.R. REP. No. 94-1341, at 13-14 (1976); see also S. REP. No. 94-698, at 13 (1976). The statute reads: "In promulgating any rule . . . with respect to a chemical substance or mixture, the Administrator shall consider and publish a statement with respect to ... the reasonably ascertainable economic consequences of the rule, after consideration of the effect on the national economy, small business, technological innovation, the environment, and public health." TSCA $\S 6(\mathrm{c})(4), 15$ U.S.C. $\S 2605(\mathrm{c})(4)$ (2006) (emphasis added). 
conform to new standards. ${ }^{40}$ This also reduces political opposition because it leaves existing investments largely untouched. ${ }^{41}$ Furthermore, regulatory agencies with limited resources may have an easier task in regulating a smaller segment of the market. On the other hand, making such distinctions also has substantial drawbacks. The approach leaves a large segment of the relevant industry minimally regulated beyond the threat of products liability, which has well known limitations in its application to toxic substances. ${ }^{42}$ The old-new distinction also inhibits desirable innovation by encouraging the continued use of the old, more dangerous technologies that are subject to less regulatory scrutiny.

In drafting TSCA, Congress chose to regulate new chemicals substantially more strictly than existing ones. TSCA's screening process applies only to new chemicals (or significant new uses of existing ones). While the PMN process is not robust, as discussed in the next part, it is at least a gesture toward gathering safety information about new chemicals, and it establishes the only point at which the agency is required to focus on particular chemicals. There is no mandatory look-back provision for existing chemicals, even though existing chemicals represent over 99 percent by volume of chemicals in commerce. ${ }^{43}$

While TSCA does include several provisions for gathering information on existing chemicals, the provisions have proven to be of limited force. For example, the test rules in section 4 of TSCA are supposed to be triggered by a priority list created by the Interagency Testing Committee, but procedural and judicial hurdles have discouraged the promulgation of rules. ${ }^{44}$ Similarly, section 8 requires reporting of studies and incidents to EPA, but the reporting is inconsistent and there is no requirement that EPA take action on the reports. In short, if TSCA's action-forcing is weak for new chemicals, it is virtually nonexistent for existing ones.

\section{Synoptic Approach}

It is ironic that TSCA has been an under-achiever among the toxics statutes because it has a carefully conceived, comprehensive, and integrated structure that was developed in response to a coherent plan to respond to the particular problems of toxic chemicals. Taken as a whole, TSCA methodically covers nearly all aspects of chemical manufacture, use, and disposal-the

40. For example, the Clean Air Act establishes new source performance standards (NSPS) which are significantly more stringent standards than the standards for existing sources. 42 U.S.C. $\S 7411$ (2006).

41. See generally Peter Huber, The Old-New Division in Risk Regulation, 69 VA. L. REV. 1025 (1983).

42. See Wagner, Choosing Ignorance, supra note 16 , at 774-76, 784-85.

43. Commission White Paper, supra note 1 , at 6.

44. The PMN standard for preventing sale of new chemicals pending additional information in TSCA section 5(e) is very similar to the standard for obtaining information on existing chemicals in section 4(a). 
identification of subjects of regulation (the Chemical Substances Inventory ${ }^{45}$ ), information generation techniques for new and old chemicals, a wide range of regulatory control options, and the coordination of regulatory action across media and across statutes-and the whole edifice is neatly tied to a single substantive regulatory standard, "unreasonable risk," or variations thereon.

Moreover, TSCA employs a "synoptic" approach, to use Professor Hornstein's term for regulation that seeks to address all aspects of an identified problem. ${ }^{46}$ The elements to be considered in taking regulatory action-human health and environmental effects, economic impact, social impact, and so onare for all practical purposes unlimited. ${ }^{47}$ Since chemicals are, after all, useful products (as opposed to pollutants), TSCA's risk-cost-benefit balancing seems appropriate, if not inevitable, for addressing the problem of regulating industrial chemicals. TSCA also requires some kind of comparative assessment of regulatory alternatives, since EPA has to choose the "least burdensome" alternative $\mathrm{e}^{48}$ and to defer to other statutes when they are effective. ${ }^{49}$ TSCA's synopticism lends further support to the dual goals of protecting health and protecting the chemical industry, by enforcing a role for the statute that is limited in stringency (unreasonable risk, least burdensome regulations) and in scope (statutory gap-filling). It also commits the agency to a fairly exhaustive investigation and analysis each time it seeks to exert regulatory control.

\section{Procedural Complexity}

A final consequence of the attempt to balance regulation and support of the chemical industry and to regulate new and old chemicals under a synoptic approach is that TSCA is procedurally complex. The procedures for rulemaking under the main regulatory authorities (section 6), the mechanics of deploying the PMN process to obtain additional data, and test rules are all predicated on specific findings by EPA. Hybrid rulemaking procedures (that is, procedures in addition to the basic notice-and-comment procedures of informal rulemaking) apply to most of EPA's actions under TSCA. And the judicial review provision is notable for adopting the "substantial evidence" standard of judicial review. This apparently procedural standard highlights the predicate findings by requiring specific justification for each. Moreover, the "substantial evidence"

45. TSCA $\S 8(b), 15$ U.S.C. $\S 2607$ (b) (2006). The Inventory is the basis for distinguishing between new and existing chemicals and uses. REACH relies on a similar device, the European Inventory of Existing Commercial Chemical Substances. European Commission Regulation 1907/2006, art. 3(20), Registration, Evaluation, Authorisation and Restriction of Chemicals, 2006 O.J. (L 396) 1 (EC) [hearinafter REACH] (defining "phase-in substance").

46. Donald T. Hornstein, Lessons from Federal Pesticide Regulation on the Paradigms and Politics of Environmental Law Reform, 10 YALE J. ON REG. 369, 386-87 (1993).

47. By contrast, the Clean Air Act has been repeatedly construed to exclude cost consideration. See Whitman v. American Trucking Ass'n, 531 U.S. 457 (2001).

48. TSCA § 6(a).

49. Id. $\S 9(\mathrm{a})$. 
standard signals Congress' wish that EPA's actions under the statute be subjected to a more skeptical approach from reviewing courts.

\section{B. TSCA's Disappointments}

TSCA has not been the comprehensive and aggressive regulator of industrial chemicals that was recommended by $\mathrm{CEQ}$, feared by industry, and predicted by both. Rather, its actual performance reflects the legislative compromises that were necessary to enact it. Many of the critical mechanisms in TSCA have not functioned or have been abandoned in practice. The goals of collecting data on potentially hazardous chemicals and of regulating them have not been met. These failings result from a range of obstacles, not least of which are the structural choices made in crafting TSCA.

\section{Information Gathering}

One of the main shortcomings of TSCA is the slow pace of the generation of new data on chemical hazards. It has been well documented that a severe data gap still exists for industrial chemicals. ${ }^{50}$ EPA and the European Commission (the latter in anticipation of REACH) undertook several studies of chemical information in the last decade, and they have uniformly reached the conclusion that basic chemical data-even for high production volume (HPV) chemicals-is only minimally available. The 1984 Toxicity Testing study by the National Academy of Sciences found in its sample that no toxicity testing was available for more than 80 percent of all toxic substances in commerce and that even a minimum data set was available for only 22 percent of HPV chemicals. ${ }^{51}$ More than a decade later, the Environmental Defense Fund (now Environmental Defense) published a report which found that a screening data set (that is, far less than would be needed to complete a risk assessment) was publicly available for only 29 percent of the one hundred HPV chemicals (greater than one million lbs/year) in their sample. ${ }^{52}$ No data or only part of the screening data set was publicly available for 71 percent of the sample. ${ }^{53}$ The Chemical Manufacturers Association (CMA, now American Chemistry Council) responded with its own study, with results that are not all that dissimilar. ${ }^{54}$ CMA found that a complete screening data set existed for 7 percent of chemicals, though others have interpreted the findings less

50. See Applegate, Bridging the Data Gap, supra note 20 at 1381-83.

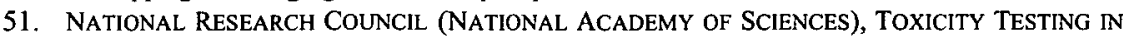
THE TWENTY-FIRST CENTURY: A VISION AND A STRATEGY 205-08 (2007).

52. ENVIRONMENTAL DEFENSE FUnd, TOXIC IGNORANCE: THE CONTINUING ABSENCE OF BasiC HeAlth Testing fOR TOP-SElling Chemicals IN THE UNITED STATES 15 (1997), available at http://www.environmentaldefense.org/documents/243_toxicignorance.pdf.

53. Id.

54. David Roe, Toxic Chemical Control Policy: Three Unabsorbed Facts, 32 ENVTL. L. REP. $10,232,10,237(2002)$. 
generously. ${ }^{55}$ EPA undertook a third study of HPV chemicals and found that "no basic toxicity information . . . is publicly available for 43 percent of the high volume chemicals manufactured in the U.S. and that a full set of basic toxicity information is available for only 7 percent of these chemicals." ${ }^{56}$

In preparing for $\mathrm{REACH}$, the European Commission sponsored several additional studies of chemical data. One study concluded that a publicly available screening base data set existed for only 14 percent of the HPV chemicals studied, less than a base set existed for 65 percent, and no data existed for 21 percent. ${ }^{57}$ Other European studies have reached conclusions similar to EPA's. ${ }^{58}$ These studies paint a remarkably consistent picture of the lack of data (at least publicly available data; the existence of private data cannot be verified) concerning HPV chemicals, the chemicals that one would expect to support the greatest amount of risk research.

These weaknesses flow from the approach and compromises Congress made in enacting TSCA. While the Senate report spoke of the need to "assure that chemicals receive careful premarket scrutiny," 59 Congress did not ultimately follow the licensing model of food and drug and pesticides laws. Enacting TSCA after several failed attempts, it instead adopted the much weaker PMN procedure. PMN does not require the creation of any new safety data; EPA must take what it is given. If EPA wants more information, then it must take the initiative and assume the burden of proving the need for that information when it seeks to restrict a new chemical or new use. ${ }^{60}$ EPA's

55. Id.

56. U.S Envtl. Prot. Agency, Office of Pollution Prevention and Toxics. Chemical hazard Data Avallability Study: What do We Really KNow about the Safety of High PRODUCTION VOLUME CHEMICALS? 2 (1998), available at http://www.epa.gov/HPV/pubs/general/ hazchem.pdf.

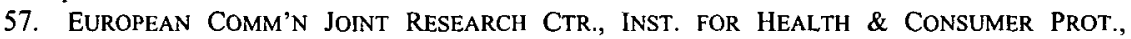
European Chem. Bureau, Public availability of Data on EU high Production Volume CHEMICALS 1, EUR 18996 EN (1999), available at http://ecb.jrc.it/DOCUMENTS/ExistingChemicals/PUBLIC_AVAILABILITY_OF_DATA/datavail.pdf.

58. EUROPEAN COMM'N JOINT RESEARCH CTR., INST. FOR HEALTH \& CONSUMER PROT., ASSESSMENT OF ADDITIONAL TESTING NEEDS UNDER REACH: EFFECTS OF (Q)SARS, RISK BASED TESTING AND VOLUNTARY INDUSTRY INITIATIVES (2003), available at http:/ecb.jrc.it/documents/ REACH/PUBLICATIONS/REACH_testing_needs_final.pdf [hereinafter ASSESSMENT OF ADDITIONAL TESTING NEEDS]; see also RPA \& STATISTICS SWEDEN, ASSESSMENT OF THE BUSINESS IMPACT OF NEW REgulations IN THE CHEMICALS SECTOR 11-14, 27-28 (2002), available at http://europa.eu.int/comm/enterprise/reach/docs/whitepaper/bia_summary-2002_06.pdf; COMM'N OF

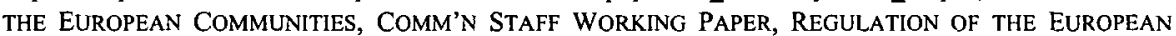
Parllament and of THE COUNCIL CONCERning the Registration, Evaluation, Authorisation AND RESTRICTIONS OF CHEMICALS (REACH), ESTABlishing A EUROPEAN CHEMICALS AGENCY AND Amending Directive 1999/45/EC and Regulation (EC) (ON Persistent ORganic Pollutants), EXTENDED IMPACT ASSESSMENT 26-27 (2003) 644 final, available at http://europa.eu.int/comm/ enterprise/reach/docs/reach/eia-sec-2003_1171.pdf.

59. S. REP. No. 94-698, at 3 (1976).

60. TSCA $\S 5(\mathrm{f}), 15$ U.S.C. $\S 2604(\mathrm{f})$ (2006). Indeed, reading the fine print, it is ultimately the courts who decide whether there should be a delay in the distribution or sale of a new chemical or new use of an existing one. See id. $\S 5(\mathrm{e})(1)$ (2). 
experience under PMN has been pretty much what one would expect from this structure. In sharp contrast to the expectations of "careful premarket scrutiny," EPA's own website acknowledges that, "[b]ecause many PMNs include little or no toxicity or fate data, the program uses several risk screening approaches to facilitate assessment in the absence of specific data." ${ }^{\circ 1}$

The weak PMN screening mechanism receives little support from the systems for gathering information about existing chemicals, which constitute the vast majority of chemicals in commerce. ${ }^{62}$ In principle, EPA has the authority to require manufacturers to submit a variety of environmental and health effects data under section 8 of TSCA, but it encounters several procedural and definitional barriers in the statute itself, and EPA has not been particularly aggressive in addressing these barriers. For example, both Congress and EPA define "substantial risk" in a way that leaves reporting largely to the manufacturer's own judgment. ${ }^{63}$ The Government Accountability Office (GAO) concluded that "EPA does not routinely assess existing chemicals, has limited information on their health and environmental risks, and has issued few regulations controlling such chemicals." ${ }^{64}$

\section{Burden of Proof}

Not only does EPA not receive adequate data, but the agency's ability actually to act on those data is both procedurally and legally difficult. In particular, TSCA's placement of the burden of proof makes regulation difficult. A demanding screening of chemicals depends critically on allocating the burden of demonstrating safety to the applicant (typically, the manufacturer), which creates a strong incentive for the applicant to come forward with required information to obtain a license to sell the product. ${ }^{65}$ TSCA's PMN neither allocates the burden to the applicant nor requires any minimum level of toxicity information-with predictably disappointing results. Instead, the burden of demonstrating unsafety is allocated to EPA. The effect of this

61. U.S. Envtl. Prot. Agency, Office of Pollution Prevention \& Toxics, http://www.epa.gov/opptintr/ar/2007-2008/reviewnewchem/index.htm (last visited October 13, 2008); see also Richard A. DeNISON, Not THAT InNOCENT: A COMPARATIVE ANalysis of CANAdian, EUROPEAN UNION AND UNITED STATES PoliCiES ON INDUSTRIAL CHEMICALS IV-1 (2007), available at http://www.edf.org/article.cfm?contentid=6147.

62. DENISON, supra note 61 , at IV-11-16.

63. See TSCA Section 8(e), Notification of Substantial Risk, Policy Clarification and Reporting Guidance, 68 Fed. Reg. 33129, 33138 (June 3, 2003). By contrast, EPA's own regulations under the pesticide statute, FIFRA, is very precise and leaves far less discretion. See 40 C.F.R. § 159.158(a) \& part 159 generally.

64. U.S. Gov't accountability OfFice, Chemical Regulations: Options Exist to IMPROVE EPA'S ABILITY to ASSESS HEALTH RISKS AND MANAGE ITS CHEMICALS REVIEW PROGRAM, GAO-05-458, 12, 18-27 (2005). See also DENISON, supra note 61, at IV-12-16.

65. The effectiveness of this technique was nicely demonstrated, albeit incidentally, by the 1984 National Academy of Sciences' study of chemical data. It found a large data gap in all regulatory areas, but the gap was strikingly smaller in food and drug and pesticides regulation, where a licensing scheme placed the burden of proof on the applicant. NATIONAL RESEARCH COUNCIL, supra note 51, at 205-208. 
allocation is intensified by additional requirements that EPA make certain specific findings on toxicity, the adequacy of other federal laws, and alternative regulatory approaches, ${ }^{66}$ As if that were not enough, EPA must also support its findings with "substantial evidence" on judicial review. 67 The legislative history expressly states that Congress "intend[ed] that the reviewing court engage in a searching review of the Administrator's reasons and explanations for the Administrator's conclusions." 68 Under these constraints, EPA has never taken a great deal of mandatory action under TSCA. ${ }^{69}$

Furthermore, mandatory restrictions came to a complete halt after the Corrosion Proof Fittings case in 1991. The Fifth Circuit (which happens to be located in the heartland of chemical manufacturing) ruled that EPA's decadelong effort to restrict asbestos (yes, asbestos) products was insufficiently supported by the record and by EPA's analysis. The court found that TSCA's "least burdensome" language created a principle that the more stringent the regulation, the greater the degree of proof to justify regulation is required ${ }^{70}$ Within this already challenging structure, the court criticized "the manner in which the EPA conducted some of its analysis," "some of the methodology employed by the EPA in making various of the calculations that it did perform," the extent of reliance on "unquantified benefits," and the degree of reliance on population exposure. ${ }^{71}$ The court was unquestionably exploiting elements that were available in the statute (the expectation of searching review, for instance), but its aggressive interpretation of those elements and attitude of extreme skepticism toward EPA's evidence have brought the mandatory program to a standstill. ${ }^{72}$ TSCA's most recent annual reports show very little activity that does not consist of voluntary programs. ${ }^{73}$

\section{Procedural Hurdles}

The procedural complexity of TSCA creates a range of barriers to regulation as well. The barriers exist, as noted above, for the basic substantive control authorities, for pre-market notification, and for post-market test rules. The test rule provision, for example, gives EPA the authority to require manufacturers to test existing chemicals, but in order to do so EPA must first make several formal findings which are subject to judicial review under the

66. TSCA § 6, 15 U.S.C. $\S 2605$ (2006).

67. Id. $\$ 19(\mathrm{~b})$.

68. H.R. REP., No. 94-1341, at 55-56 (1976); H.R. REP. No. 94-1679, at 96 (1976); see also S. REP. No. 94-698, at 28 (1976).

69. U.S. GOV'T ACCOUNTABILITY OFFICE, supra note 64, at 27-29.

70. Corrosion Proof Fittings v. EPA, 947 F.2d 1201, 1220 (5th Cir. 1991).

71. Id. at 1216-1219.

72. Under TSCA's judicial review provisions, the challenger of a regulation can bring suit on its home turf. TSCA $\S 19$ (a)(1)(A). This makes it very difficult for EPA to obtain review in other courts, and it has made the Fifth Circuit, covering Texas and Louisiana, the de facto national court for TSCA.

73. U.S. Envtl. Prot. Agency, Office of Pollution Prevention \& Toxics, supra note 61. 
demanding "substantial evidence" standard. ${ }^{74}$ The requirement that EPA demonstrate that the chemical "may present an unreasonable risk," and thus needs additional information to make a decision about regulation, creates a regulatory Catch-22: EPA must have chemical information in order to prove that it needs it, but it needs the information because it does not have it. ${ }^{75}$ As a result, EPA has required testing of fewer than two hundred out of thousands of existing chemicals, ${ }^{76}$ and of those two hundred, one hundred and forty were imposed by rule and sixty by consent. ${ }^{77}$ EPA's current website finds it necessary to "redefine success" under its chemical testing program by including voluntary approaches in its totals. ${ }^{78}$

Here we see the effects of congressional choices in the creation of TSCA. EPA's procedural burden in TSCA is no accident, and it reflects two important legislative compromises. First, when addressing complex and technically arcane subjects, Congress inevitably delegates relatively broad powers to administrative agencies, because it can only provide limited substantive constraints. Therefore, Congress also imposes procedural devices to ensure its ability to exercise continuing oversight or indirect control to keep the agency's actions in line with the original legislative bargain. ${ }^{79}$ Thus, the procedural barriers in TSCA reflect an intentional effort to limit the scope of the eventual regulation of toxic chemicals. Second, the original drafters of TSCA clearly recognized the asymmetry between the government and the regulated industry with respect to chemical information, which is exactly why they emphasized the need to generate data and located responsibility for doing so with industry. However, the final text reflects a compromise between the asserted goal of industry responsibility and economic protection of that industry. ${ }^{80}$ The central mechanisms of that compromise are the allocation of the burden of proof to EPA and the legislatively-mandated procedures EPA is required to follow before undertaking virtually any agency action under TSCA. Professors McCubbins, Noll, and Weingast observed,

74. The more flexible "arbitrary, capricious" standard, which is typical for decisions of this kind, was provided in the original Senate bill, S. REP. No. 94-698, at 28 (1976). Review was made more rigorous in the negotiations with the House version of the bill, H.R. REP. No. 94-1341, at 17-18 (1976); see also H.R. REP. No. 94-1679, at 61 (1976).

75. Applegate, Perils, supra note 24, at 315-30.

76. The TSCA Inventory contains about sixty-two thousand chemical substances, but the majority are of limited regulatory significance. James W. Conrad, Jr., Open Secrets: The Widespread Availability of Information About the Health and Environmental Effects of Chemicals, 69 LAW \& CONTEMP. PROBS. $141,143-45(2006)$.

77. Richard A. DEnison, High Hopes, Low Marks: A Final Report CaRd on the HPV ChEMICAL CHALlENGE 6 \& $\quad$ n. 3 (2007), available at http://www.edf.org/documents/6653 HighHopesLowMarks.pdf; U.S. Gov'T ACCOUNTABILITY OFFICE, supra note 64, at 18.

78. EPA, Office of Pollution Prevention \& Toxics, supra note 61.

79. Lisa S. Bressman, Procedures as Politics in Administration Law, 107 CoLUM. L. REV. 1749 , 1752-53, 1768-71 (2007).

80. Wendy Wagner, When All Else Fails: Regulating Risky Products Through Tort Litigation, 95 GEO. L.J. 693, 697 (2007). 
Because policy decisions depend on what information is available to the agency, structure and process determine the quantity, quality, and completeness of available information and the extent to which policy decisions must be supported by this information. Political principals can control the influence of a constituency by using structure and process to affect the dependence of the agency on information the constituency supplies . . . . More elaborate procedures are generally regarded as favorable to regulated industries. Because industries possess much of the information relevant to regulatory decisions, elaborate processes give them more power by increasing the importance of that information. ${ }^{81}$

The authors, in fact, offer TSCA's rejection of strong pre-market screening as an example of strategic procedural complexity. ${ }^{82}$

As one would expect, the greatest number of substantive and procedural requirements apply to the imposition of actual restrictions. Not only are several specific findings demanded, but EPA must go through an elaborate hearing process (designated "informal;" in fact, anything but), including oral testimony and even cross-examination. And, in case the point was not clear enough, these procedures are specially called out for enforcement in the judicial review section, ${ }^{83}$ ensuring that EPA will always go though the entire panoply of potential procedures to avoid reversal after investing in a lengthy administrative process, as happened in Corrosion Proof Fittings.

\section{Voluntary Measures}

While the formal procedures of regulation have failed, an informal practice of consent orders for further testing has developed, ${ }^{84}$ which industry and EPA regard as quite satisfactory for obtaining necessary data. Chemicals are screened for their structural similarities to chemicals with known hazards, and requests for additional information are made accordingly. ${ }^{85}$ In addition, voluntary control actions are sometimes taken. ${ }^{86}$ Nevertheless, the GAO reported in 2005 that only about 20 percent of new chemicals receive detailed

81. Matthew D. McCubbins, Roger G. Noll \& Barry R. Weingast, Structure and Process, Politics, and Policy: Administrative Arrangements and the Political Control of Agencies, 75 VA. L. REV. 431, $440-41,469$ (1989).

82. Matthew D. McCubbins, Roger G. Noll \& Barry R. Weingast, Administrative Procedures as Instruments of Political Control, 3 J. L. ECON. \& ORG. 243, 268-69 (1987).

83. TSCA $\S 19(\mathrm{c})(1)(B)(\mathrm{ii}), 15$ U.S.C $\$ 2618(\mathrm{c})(1)(\mathrm{B})(\mathrm{ii})(2006)$.

84. DENISON, supra note 77, at 6; see also EPA, Office of Pollution Prevention \& Toxics, TSCA Chemical Testing Program Objectives, http://epa.gov/opptintr/chemtest/pubs/vision.htm (last visited October 16, 2008); U.S. Envtl. Prot. Agency, Section 8 of TSCA, http://www.epa.gov/opptintr/tsca8e (last visited Oct 16, 2008); U.S. Envtl. Prot. Agency, TSCA Section 5 New Chemicals Program, http://www.epa.gov/opptintr/newchems (last visited October 16, 2008); U.S. Envtl. Prot. Agency, Chemical Information Collection and Data Development (Testing), http:/www.epa.gov.opptintr/ chemtest/index.htm (last visited October 16, 2008).

85. Janey Cohen, EU, Canada on "Leading Edge" of Paradigm Shift on Chemical Regulation, 30 INTL. ENVT. REP. (BNA) 779 (Oct. 3, 2007); Conrad, supra note 76, at 143-144.

86. U.S. GOV'T ACCOUNTABILITY OFFICE, supra note 66, at 16-17. 
review. ${ }^{87}$ While simply counting chemicals and tests may be an imperfect measure, it is suggestive, and the GAO concluded that "EPA lacks sufficient data to ensure that potential health and environmental risks of new chemicals are identified." 88

In principle, of course, it should not matter whether chemical information is obtained from mandatory or voluntary mechanisms. Neither reliance on voluntary programs nor the absence of formal action to obtain data is proof that the data do not exist. Industry asserts that voluntary programs have in fact been highly successful, ${ }^{89}$ and cooperative programs clearly have their uses. ${ }^{90}$ However, since the testing is voluntary, EPA has little ability to fill gaps that remain. For example, EPA's touted HPV Challenge program has been severely criticized by one of its co-sponsors, Environmental Defense, as providing far fewer data than promised, and years late, ${ }^{91}$ and EPA's Inspector General reports that EPA's many voluntary programs lack the kinds of data collection and internal controls that are needed to determine whether the programs are in fact successful. ${ }^{92}$

In sum, TSCA is as ungainly as it was designed to be. The central legislative compromise was that TSCA would grant comprehensive authority to EPA but that it would be difficult to use. As it turned out-and, in retrospect, not surprisingly - the difficulty of use in essence trumped the comprehensive authority; the authority is not really comprehensive if it cannot be deployed. As a result, despite CEQ's careful analysis in Toxic Substances and the high hopes of TSCA's proponents, TSCA has substantially under-performed as a generator of chemical information and a regulator of industrial chemicals. The great majority of chemicals remain largely unstudied for any but the most obvious effects, and EPA would have tremendous difficulties in restricting dangerous uses, even if these effects were known.

87. Id. at $17-18$.

88. Id. at 10. This is not new. In 1983, the Office of Technology Assessment reported that about half of PMNs contained no toxicity information at all, and less than $20 \%$ contained data on long-term toxicity. OfFice of TECh. Assessment, THE INFORMATION CONTENT of PRE-MANUFACtURE Notices 6-7, 49-54 (1983).

89. See Cohen, supra note 85 (quoting industry spokespeople); Conrad, supra note 76, at 143.

90. Conrad, supra note 78, at 143-46 (requiring disclosures), 153-57 (encouraging voluntary programs); U.S. Gov'T ACCOUNTABILITY OFFICE, supra note 66, at 40-43; U.S. Envtl. Prot. Agency, Office of Pollution Prevention \& Toxics, supra note 61.

91. DENISON, supra note 77.

92. U.S. ENVTL. PRot. AgenCy OfFice of INSPector General, EVAluation Report:

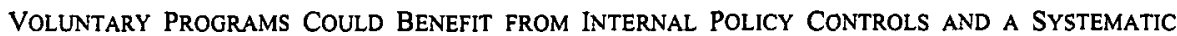
MANAGEMENT APPROACH, Report No. 2007-P-00041 (Sept. 25, 2007), available at http:// www.epa.gov/oig/reports/2007/20070925-2007-P-00041.pdf. 


\section{ANTITHESIS: REACH AND ITS PROMISE}

\section{A. The EU Response to TSCA}

REACH was designed to correct weaknesses in the existing chemical regulatory system in Europe. Some of the weaknesses were distinct to the European system. For example, prior to $\mathrm{REACH}$, an array of complicated directives and regulations covered the chemical industry, and the public expressed a widespread desire to reduce animal testing. However, REACH was also designed to correct the weaknesses apparent in the U.S. experience. While neither the White Paper nor the formal explanatory memorandum that accompanied the actual legislation mention TSCA by name, it is hard to read them as anything other than an effort to make REACH everything that TSCA was not.

The EU spent nearly a decade developing REACH. The European Commission identified the need for the regulation, undertook a thorough study of the issues, and proposed the legislation. The REACH proposal went through the complex European legislative process and received the approval (with amendments) of the other main governmental organs (the Council and the European Parliament) in December 2006. The legislation is in the form of a regulation (as opposed to a directive), which means that it is self-executing and does not require further legislative action by each member state. The EU uses regulations when uniformity is of particular importance, and an important objective of REACH was to harmonize the existing system of multiple and overlapping regulatory systems that was believed to hamper the competitiveness of the Europe-wide industry.

Along with its commitment to centralization, REACH maintains an active role for the member states. Member state regulators (known as "Competent Authorities" in REACH) participate in most of the regulatory phases in a variety of ways, but they may not take unilateral action, in deference to REACH's goal of harmonization. A new European Chemicals Agency (ECHA), headquartered in Helsinki, manages and coordinates all of the aspects of the process. ECHA's role is primarily administrative, but it also provides scientific and technical advice. The latter role involves committees on risk assessment and on socio-economic analysis, which are made up of outside experts. ${ }^{93}$ ECHA's regulatory decision-making authority is limited to the more technical aspects of REACH (such as the evaluation phase, described below); decision-making authority at the more policy-rich phases is reserved for the Commission and the member states acting in concert. ${ }^{94}$

93. REACH, supra note 45 , at art. 64 .

94. See EUROPEAN COMM'N, REACH IN BRIEF: HOW WILL REACH WORK? WHAT ARE THE COSTS AND BENEFITS? WHAT is THE STATE OF PLAY? 14 (September 15, 2004), available at http:// ec.europa.eu/enterprise/reach/docs/reach/reach_in_brief-2004_09_15.pdf [hereinafter REACH iN BRIEF] (describing the structure and role of ECHA). 
While it simplified the existing regulatory structure for chemicals, $\mathrm{REACH}$ is by no means a simple piece of legislation. For present purposes, the basic regulatory process breaks down into four constituent parts, reflected in the elements of the $\mathrm{REACH}$ acronym: registration, evaluation, authorization, and restrictions. The first phase, registration, is primarily a data-gathering procedure. It covers all chemicals produced or imported in quantities above one metric ton per year, both new and existing (or "phase-in"), as well as certain substances found in other products. There are various exemptions for low-risk chemicals and polymers, but the ECHA expects to need to register thirty thousand chemicals and review eighty thousand dossiers by $2011 .{ }^{95}$

Applications for the registration of any chemical must include a technical dossier, which is comprehensive information on the chemical's inherent properties, including a base set of toxicological information, graduated by production volume. For chemicals produced in quantities above ten metric tons, a much more extensive Chemical Safety Report is required, which includes toxicology and exposure data, as well as measures to reduce risks from the chemical. ${ }^{96}$ Chemical data, including those obtained in registration, is shared up and down the supply chain to avoid unnecessary testing. ${ }^{97}$

The second phase, evaluation, involves three basic steps: an automatic "completeness check" for technical compliance with the REACH requirements; a dossier evaluation, which is essentially a quality control effort to assure that objectives like avoidance of animal testing and data sharing have occurred; and substance evaluation, which examines the risks posed by a substance and the measures taken to control the risks. ${ }^{98}$ Evaluation leads to the two final phases.

Authorization applies to substances "of very high concern" (VHC). ${ }^{99}$ VHC substances include carcinogens, mutagens, and reproductively toxic (CMR) substances; persistent, bioaccumulative, or toxic (PBT) substances; very persistent or very bioaccumulative ( $\mathrm{vPvB}$ ) substances; persistent organic pollutants (POPs); and other chronic hazards. Authorization is not limited to chemicals that meet the registration threshold amount of one metric ton. The primary objective of authorization is to ensure the progressive replacement of VHCs with safer alternatives; therefore, the centerpiece of the process is analysis of substitute substances. Each proponent of a VHC chemical must present a replacement chemical or at least a research plan for alternatives; if no alternatives are in prospect, then the chemical's use must be justified under a cost-benefit test. In addition, authorization requires that the substance be

95. EUROPEAN COMM'N, QUESTIONS AND ANSWERS ON REACH 3 (July 2007), available at http://ec.europa.eu/environment/chemicals/pdf/qa.pdf.

96. REACH, supra note 45 , at annex I.

97. REACH IN BRIEF, supra note 94, at 7; REACH, supra note 45, at arts. 5-14, 31-36.

98. REACH IN BRIEF, supra note 94, at 8-9; REACH, supra note 45 , at arts. 40-54.

99. For authorization, REACH IN BRIEF, supra note 94 at 9-10; REACH, supra note 45 , at arts. 55-66. The term "very high concern" appears in REACH article 55. For Restrictions see REACH IN BRIEF, supra note 94, at 10; REACH, supra note 45, at arts. 67-73. 
"adequately controlled," and if it cannot be adequately controlled 100 (CMR substances, by definition, cannot be), then, again, its benefits must outweigh its risks. ECHA expects that about 1,500 substances will require authorization. It is expected that VHC substances will be banned entirely, authorized for a limited period, or authorized for very specific uses and conditions.

The final phase is restriction. While the objective of authorization is replacement, substances that are not subject to authorization but nevertheless pose hazards in their manufacture or use may have European Community-wide restrictions imposed on them to assure that health and environmental risks remain at acceptable levels. Such restrictions may be imposed centrally if the Commission, in cooperation with the member states, determines that the risk is not adequately controlled and that it needs to be addressed at the Communitywide level. The legal standard for acceptability is not stated ${ }^{101}$ other than a general commitment to a "high level of protection." Restrictions represent REACH's "safety net," or last resort, for ensuring chemical safety. ${ }^{102}$

\section{B. REACH as the Anti-TSCA}

REACH adopts several techniques that tacitly reverse the TSCA approach, the most important of which are eliminating the distinction between new and existing chemicals, shifting the burden of proof for producing information, and requiring a demonstration of safety by the proponent of a chemical.

\section{Existing Uses}

In contrast to the approach chosen by the U.S. Congress in TSCA, REACH explicitly seeks to eliminate the distinction between existing and new chemicals (and uses). Its purpose is to remedy the data gap for existing chemicals ${ }^{103}$ - what the White Paper calls "the burden of the past"104_which will permit the application of a single, high level of safety to all chemicals, new and old. The general principle that chemicals must be shown to be safe before use also means that existing chemicals are subject to the same rigorous standards that a new chemical would be. Retrospective examination of existing substances or activities is inevitably a daunting task, especially when there are new standards to apply. The difficulty of this ambition accounts for the frequency of "grandfathering" language in regulatory statutes. TSCA, for example, grandfathers existing chemicals by imposing a screening procedure (the PMN process) only on new chemicals. REACH tackles the challenge of

100. REACH, supra note 45 , at arts. $60(4), 64(4)(a)-(b)$.

101. REACH, supra note 45 , at art. $68(1)$.

102. Id.

103. The White Paper defines "burden of the past" as "[ $t$ ]he 30,000 'existing' chemicals estimated to be on the EU market, for which little or no information is available, in particular about their long-term effects on human health or the environment." Commission White Paper, supra note 1, at 28.

104. Id. 
revisiting existing chemicals to generate information and evaluate safety by "implement[ing] a step by step process to address the burden of the past and develop adequate knowledge for existing substances that industry wants to continue marketing." 105 Over an eleven-year period, regulatory authorities are required to examine all thirty thousand existing chemicals that are produced in volumes greater than one metric ton, and to categorize and evaluate them as they would new chemicals. Much of the controversy over REACH, and much of the administrative challenge, is the insistence on applying new standards of information and assessment to existing chemicals.

\section{Generation of New Information}

A second fundamental difference between TSCA and REACH is the approach to regulating the vast range of chemicals. While TSCA's preamble states that the responsibility for generating chemical information should lie with the manufacturer, the opposite has been the case in practice; instead the regulator is held to a high standard for generating information. TSCA requires manufacturers to submit data only when there are new uses, and places substantial burdens on EPA when it seeks to generate or require more. REACH takes the opposite tack. Since REACH seeks to take a fundamentally precautionary approach to protecting the environment and human health when data are uncertain, REACH demands that better information be generated and that, in the absence of such information, chemicals be highly restricted or prohibited outright. As a consequence, the responsibility for generating new information is allocated to the proponent of the use of the chemical.

REACH makes the generation of information a priority. "The lack of data on the hazardous properties of chemicals was the driving force behind the development of a new chemicals policy in the EU," 106 and so REACH moves the status quo from "no data, no problem" to "no data, no market" (the title of article 5 of REACH):

Subject to Articles 6, 7, 21 and 23, substances on their own, in preparations or in articles shall not be manufactured in the Community or placed on the market unless they have been registered in accordance with the relevant provisions of this Title where this is required.

As discussed above, registration is primarily an information-provision process, ${ }^{107}$ the centerpiece of which is the submission by applicants of a Chemical Safety Report ${ }^{108}$ for existing substances produced in quantities over ten metric tons. In this way, REACH attempts to eliminate the old-new distinction in chemical data, at least for medium and high production volume

105. Id. at 7-8.

106. ASSESSMENT OF ADDITIONAL TESTING NEEDS, supra note 58 , at 5 .

107. REACH, supra note 45 , at art. 10

108. Id. at art. 14 . 
chemicals, and requires that substantive information be produced for all chemical uses.

\section{Burden of Proof of Safety}

The allocation of burden of proof is more than just a means to a regulatory end; it is also a normative position. Burden of proof expresses a fundamental public policy by placing the responsibility for determining a chemical's safety either with the manufacturer or with the government, making it either an essentially private or essentially public decision, respectively. The normative burden of proof also gives direction to regulators in their substantive evaluation of a chemical, telling them how selective to be, how doubts are to be resolved, and how judgment is to be exercised.

The allocation of the burden of proof has practical consequences for the number of chemicals that will be approved, and the terms under which they will be approved, for use. Most importantly, it has the instrumental effect of encouraging one party or the other to generate information to persuade the decision-maker, because the party with the burden must move the status quo. For example, a status quo of no-approval with the burden on the private applicant will encourage the applicant to provide the information needed to demonstrate that its product is safe and effective for its intended purpose. In contrast, placing the burden of proof on the regulator has the opposite effect on private party behavior, encouraging secrecy or ignorance. It is affirmatively up to the agency to seek out information or else to abandon regulatory effects.

TSCA, as discussed above, places the burden of proof squarely on the regulator to support a finding of the existence of an "unreasonable risk." Professor Wagner has called TSCA "unprecautionary" on this and other grounds, ${ }^{109}$ and the burden of proof clearly contributes to TSCA's ineffectiveness. Before $\mathrm{REACH}$, European chemicals regulation placed the burden of proof in the same "unprecautionary" manner. As the Commission's White Paper said,

[t]he current approach requires authorities to provide convincing arguments, usually in the context of a risk assessment, before restriction measures are taken. Their task is further complicated because the current system does not encourage industry to support the assessment. On the contrary, delaying the process is 'rewarded' with an extended marketing period. ${ }^{10}$

The requirement for specific findings and the "substantial evidence" standard of judicial review in TSCA intensify the general burden on the agency and therefore increase its reluctance to regulate.

109. Wendy E. Wagner, The Precautionary Principle and Chemical Regulations in the U.S., 6 HUM. \& ECOLOGICAL RISK ASSESSMENT 459, 468 (2000) (suggesting that TSCA embodies an "unprecautionary principle").

110. Commission White Paper, supra note 1 , at 19. 
REACH once again takes the opposite approach. Article 1 of the legislation states:

[This Regulation] is based on the principle that it is for manufacturers, importers and downstream users to ensure that they manufacture, place on the market or use such substances that do not adversely affect human health or the environment. ${ }^{111}$

REACH thus requires manufacturers to take affirmative, substantial action in order to retain their markets. The overall normative message, therefore, is that chemical risks should be controlled, eliminated, mitigated, or justified by their creators.

While registration itself "does not imply any form of approval by the Agency of the assessment or use of the substance," 112 chemicals of "very high concern" (that is, which are subject to authorization based on intrinsic properties of toxicity, persistence, or bioaccumulation) require actual approval. ${ }^{113}$ That approval involves adequate control of a hazardous chemical and a substitution plan. As we have seen, if no substitutes are in prospect, then the manufacturer must present a socio-economic justification for continued marketing, and without that, the use is denied approval. ${ }^{114}$ To turn a phrase, where TSCA urges caution in regulating industrial chemicals, REACH urges precaution in approving them.

Nevertheless, REACH is not entirely consistent in this regard. The restriction procedure, the safety net of the overall $\mathrm{REACH}$ process, ${ }^{115}$ in which the Commission imposes general limitations on the use of a chemical, seems to return to the TSCA burden of proof. The Commission first assembles a dossier on the effects of the chemical, based on the manufacturer's chemical safety report. If the dossier "demonstrates that action on a Community-wide basis is necessary," then restrictions are imposed. ${ }^{116}$ The grammatical construction of the text - "if this dossier demonstrates"- and use of the term "necessary" suggest that the burden is on the Commission to justify action, which is a departure from the overall objective to place the burden on industry. ${ }^{117}$ Moreover, the administrative process within the Commission ("comitology," in Euro-jargon) for imposing restrictions (opinions of Risk Assessment and SocioEconomic Analysis Committees must be solicited and responded to ${ }^{118}$ ), and the

111. REACH, supra note 45 , at art. 1(1)(3).

112. REACH IN BRIEF, supra note 94 , at 6 .

113. REACH, supra note 45 , at art. 55 .

114. Id. at arts. 55,60 .

115. Commission Proposal, supra note 1, at 12,16.

116. REACH, supra note 45 , at art. 69(3).

117. Veerle Heyvaert, Guidance without Constraint: Assessing the Impact of the Precautionary Principle on the European Community's Chemicals Policy, 6 Y.B. OF EUR. ENVTL. LAW 27, 50-56 (2006) [hereinafter Guidance without Constraint].

118. REACH, supra note 45 , at art. 64 . 
review process with other organs, adopt a level of procedural complexity ${ }^{119}$ that in some ways rivals TSCA. ${ }^{120}$

\section{New Ideas in REACH}

REACH also differs from TSCA by adopting several important regulatory techniques that were not yet available at the time of TSCA's enactment. REACH thus offers a particularly interesting glimpse of the next generation of chemicals regulation as enacted by the governments of industrialized countries. A whole range of provisions in $\mathrm{REACH}$, especially the burdens of information production and the burden of proof, reflect a more general decision to take a precautionary approach, that is, explicitly to permit regulation of chemicals in advance of full information as a means of affording greater protection to human health and the environment. REACH also puts an emphasis on the continuing development of new and safer alternatives, and on the public's right to know the hazards to which they are exposed.

\section{The Precautionary Principle}

Precaution made its first major appearance as a distinct principle of international environmental law in the 1985 Vienna Convention for the Protection of the Ozone Layer, which recognized the continuing scientific uncertainty surrounding ozone depletion but insisted on moving forward nevertheless to meet this environmental threat. It did not enter the American environmental consciousness until the late 1990s. Thus, while the "precautionary principle" was not available as a concept to the drafters of TSCA, it was an important foundational concept for the drafters of REACH. ${ }^{121}$ The EU Treaty incorporates the precautionary principle in the basic statement of European environmental policy, ${ }^{122}$ and the Commission has issued an

119. Id. at arts. 70, 73, 133(4). See also Heyvaert, Guidance without Constraint, supra note 117, at 49; Veerle Heyvaert, No Data, No Market: The Future of EU Chemicals Control under the REACH Regulation, 9 ENVTL. L. REV. 201, 203 (2007).

120. The Regulatory with Scrutiny review procedure, required by REACH art. 133(4), involves both another layer of internal Commission review, and also substantive involvement by the European Parliament and Council. Council Decision 1999/468/EC, art. 5, 1999 O.J. (L 184) 23, 25. A controversial restriction could be considerably delayed through this process.

121. While the Precautionary Principle clearly "played a highly prominent role" in the adoption of REACH, Professor Heyvaert persuasively challenges the assumption that the Precautionary Principle actually determined to content of the legislation in ways that would not have happened without the formal adoption of the principle in European law. Heyvaert, Guidance without Constraint, supra note 117, at 51. For present purposes, the influence of the Precautionary Principle will be considered relevant to the extent of its consistency with REACH provisions (which Heyvaert finds) and even providing "a language in which to express [pro-protection] concerns." Id. at 45.

122. Consolidated Versions of the Treaty of European Union and of the Treaty Establishing the European Community, art 174(2), Dec. 29, 2006, 2006 O.J. (C 321) I [hereinafter Treaty of European Union]. 
interpretive guide to the precautionary principle, ${ }^{123}$ which has gained general acceptance from the other principal organs of European governance, including an enthusiastic judicial reception. ${ }^{124}$ The authors of REACH expressly recognized the importance of the precautionary principle to the new regulatory regime, ${ }^{125}$ and article 1 of REACH states that its "provisions are underpinned by the precautionary principle." 126

The central purpose of the precautionary principle is to authorize regulatory action in the face of scientific uncertainty. The most widely accepted version of the principle reads:

In order to protect the environment, the precautionary approach shall be widely applied by States according to their capabilities. Where there are threats of serious or irreversible damage, lack of full scientific certainty shall not be used as a reason for postponing cost-effective measures to prevent environmental degradation. ${ }^{127}$

As Professor Fisher explains, this means that, procedurally, no evidence of harm is not to be equated with evidence of no harm. ${ }^{128}$ For a regulatory system that is committed to preventing harm, lack of data cannot justify inaction; rather, the (relative) safety of a chemical should be demonstrated by its proponents, typically its manufacturers. Rhetorically, the precautionary principle takes away the argument that a chemical should be approved because its harmful effects remain uncertain. Supported by the allocation of the burden of proof, REACH takes this general approach. For example, REACH directs that safety assessments be based on the information that gives the greatest cause for concern. ${ }^{129}$ In contrast, the findings and substantial evidence requirements in TSCA by their nature declare that no evidence of harm has the same procedural effect as evidence of no harm. As a result, TSCA has spawned an entire industry of raising uncertainties as a defense against regulation.

Although REACH rests firmly upon a precautionary approach, the European Commission's incorporation of the precautionary principle is not

123. Communication from the Commission on the Precautionary Principle, COM (2000) 1 final (Feb. 2, 2000). The Commission's interpretation of the Precautionary Principle represents a very modest version or interpretation of the principle. More aggressive interpretations exist, but they do not form the basis of REACH. See, e.g., John S. Applegate, The Taming of the Precautionary Principle, 27 WM. \& MARY ENVTL. L.J. 13, 17-20 (2002).

124. See Elizabeth Fisher, Precaution, Precaution Everywhere: Developing a "Common Understanding" of the Precautionary Principle in the European Community, 9:1 MAASTRICHT J. OF EUR. \& COMP. L. 7, 12 (2002); Heyvaert, Guidance without Constraint, supra note 117, at 28, 33, 35.

125. Commission White Paper, supra note 1 , at 5.

126. REACH, supra note 45, at art. 1(3).

127. United Nations Conference on Environment and Development, June 3-14, 1992, Rio Declaration on Environment and Development, If 15, U.N. Doc A/CONF.151/26 (June 14, 1992) [hereinafter Rio Declaration].

128. Fisher, supra note 124 , at 9.

129. REACH, supra note 45 , at annex $I, \S \S 1.1 .4,3.1 .5$ (suggesting general provisions for safety assessments and chemical safety reports); EUROPEAN COMM'N, QUESTIONS AND ANSWERS ON REACH, supra note 95 , at 3 . 
intended to be a wholesale revision of the philosophy of environmental protection. Instead, by placing the precautionary principle within the larger framework of risk analysis, limiting the use of the principle to situations of demonstrable uncertainty, and especially by requiring follow-up research to resolve uncertainties, the Commission indicated that the precautionary principle is primarily a means of avoiding stalemate and inaction in the common situation of scientific uncertainty. ${ }^{130} \mathrm{REACH}$ maintains the common regulatory approach of aiming for proportionate controls in applying the precautionary principle. Thus, rather than opting for a stricter approach to the precautionary principle that would ban all uses in the face of uncertainty, the authorization and restriction processes mandate some economic balancing of risks and benefits to permit some uses to go forward, subject to future revision and development of alternatives. In effect, REACH interprets the precautionary principle to be based on scientific inquiry that establishes the existence of a potential harm, and then to require follow-up inquiry to resolve uncertainties if regulatory action goes forward without full certainty.

\section{Substitution of Safer Alternatives}

The REACH approach to chemical regulation also plays out in its robust provisions for the ongoing development of alternatives and risk reduction. REACH does not seek to avoid all use of industrial chemicals or to achieve a chemical-free future. Instead, like TSCA, it seeks to limit the risks posed by chemicals in commerce by deploying substantive standards that acknowledge both the utility and the dangers of these substances. Unlike TSCA, however, $\mathrm{REACH}$ also adopts regulatory techniques that expressly provide strong incentives for the development of new and toxicologically safer chemicals. ${ }^{131}$ Dangerous chemicals are to be "progressively replaced by suitable alternative substances or technologies where these are economically and technologically viable." ${ }^{\text {132 }}$ The approach of progressive substitution not only limits political opposition and possibly the economic dislocation that would accompany a strategy of simply banning dangerous chemicals, but it also takes advantage of, and indeed incentivizes, innovation in the chemical industry.

REACH seeks to achieve the goal of substitution principally by allocating the overall burden of demonstrating safety, recognizing that safer chemicals will be easier to justify. In addition, manufacturers are held generally responsible for the safety of their chemicals. Furthermore, manufacturers must

130. Communication from the Commission on the Precautionary Principle, supra note 123, at 13$15,20-21$.

131. Commission White Paper, supra note 1, at 5, 8 .

132. REACH, supra note 45, art. 55; see also Commission White Paper, supra note 1, at 8 (stating that "[i]t is essential to promote the competitiveness of the chemical industry and encourage innovation, and in particular the development of safer chemicals."). TSCA, in contrast, emphasizes innovation generally and the concern is avoidance of negative effects on innovation rather than taking affirmative steps to direct it. TSCA $\S 2(b)(3), 15$ U.S.C. $\S 2601(b)(3)(2006)$. 
provide hazard information to downstream users of chemicals and to consumers. ${ }^{133}$ As California has found with its Proposition 65, pointed public information is a strong incentive to use only the safest chemicals. ${ }^{134}$ The registration requirement is thus itself an incentive to use safe and well-tested substances, since the registration information is public and the absence of testing will be exposed-and must be remedied-through the registration process.

The authorization procedure that is required for the most dangerous chemicals creates an even more intense regulatory incentive to find safer substitutes. Authorization is public, expensive, and if the chemical is not adequately controlled, the manufacturer must show that benefits outweigh costs. Especially in the context of the normative messages incorporated into the regulation, this public analysis is likely to be highly critical of the manufacturers. Finally, authorization and restriction require the disclosure and analysis of substitute substances. ${ }^{135} \mathrm{~A}$ lawyer at a European branch of an American law firm was recently quoted as saying that companies that make a chemical of high concern must "be ready for a long and never-ending battle" to continue to market it, ${ }^{136}$ which is surely a powerful incentive to look for substitutes.

\section{Transparency and the Right to Know}

The efforts at creating safer alternatives are bolstered by the robust "rightto-know" provisions in REACH. Since the passage of TSCA, environmental law has seen the development of right-to-know legislation as a way to regulate chemicals. Like burden of proof, right-to-know laws have both normative and instrumental purposes. The normative purpose gives the legislation its name: citizens are entitled to know the chemicals to which they are exposed and the chemicals' effects. Since they are potentially affected, citizens have a right to respond to the information with individual choice (such as purchasing),

133. Commission White Paper, supra note 2, at 8; see also REACH, supra note 45, at preamble paras. 13, 33, 47, 49, 50, and 64 .

134. See generally Clifford Rechtschaffen \& Patrick Williams, The Continued Success of Proposition 65 in Reducing Toxic Exposures, 35 ENVTL. L. REP. 10850 (2005) (continuing effectiveness of Prop 65); Carl Cranor, Information Generation and Use under Proposition 65: Model Provisions for Other Postmarket Laws? 83 IND. L.J. 609, 613-14 (2008). Industry continues to resist such measures vigorously. The Bush Administration EPA recently published a rule that reduces considerably the information that must be reported to EPA under the Toxics Release Inventory. Toxics Release Inventory Burden Reduction Final Rule, 71 Fed. Reg. 76,932 (December 22, 2006) (to be codified at 40 C.F.R. pt. 372).

135. REACH, supra note 45 , at arts. $55,60(4)-(5)$ (referring to authorization), 68(1), Annex XVXVII (referring to restrictions). Massachusetts directly encourages substitution through the Toxics Use Reduction Act (TURA), Mass. Gen. Laws ch. 21 ( 2004 \& Supp. 2006), which requires the creation of actual toxics reduction and substitution plans, which are not necessarily available to the public, to encourage internally motivated action by firms rather than to generate public pressure.

136. Pat Phibbs-Rizzto, European Hazardous Chemicals Lists May Give Clues on 'Very High Concern' Items, 30 INT'L. ENVTL. REP. (BNA) 396 (May 16, 2007). 
litigation, and political action. The instrumental purpose of right-to-know laws is to embarrass the users or emitters of chemicals, which has been shown in California and elsewhere to act as a strong incentive to reduce or replace the chemicals. ${ }^{137}$ The seemingly universal availability of the internet-another post-TSCA development-magnifies the potential of public information to embarrass producers and to affect individuals' decisions and to facilitate individual and collective action.

REACH relies on a range of mechanisms to facilitate and require the flow of information up and dcwn the entire supply chain, ${ }^{138}$ as well as to government agencies and the general public. ${ }^{139}$ It relies heavily on the existence of publicly available data and its ready accessibility to anyone via the internet. ${ }^{140}$ Public information is another spur to industry to develop new, safer substitute products. ${ }^{141}$ Not only can public information be expected to create a demand among the general public to reduce the use of toxic substances, but the greater availability of specialized information will result in legal pressurethrough regulation or litigation-by non-governmental organizations to reduce the use of toxic chemicals. ${ }^{142}$

\section{Reduced Animal Testing}

While the use of animals to test the toxicological effects of chemicals is a major concern among a relatively small segment of the U.S. population, the issue is quite salient in Europe. As a result, reduction of animal testing is a major stated objective of REACH. ${ }^{143}$ This creates a dilemma: the reduction of animal testing runs directly counter to the commitment to generate more test data. Since testing has always been a major cost for industry, however, concern over animal testing has resulted in some strange political bedfellows. Together, industry and animal rights groups engineered several regulatory innovations to reduce the need for testing while supporting a strongly data-based regulatory system. These include mandatory data sharing, "one substance one registration,"144 only invertebrate and in vitro testing for the lowest production

137. Cranor, supra note 134, at 613-14; see also Rechtschaffen \& Williams, supra note 134, at 10850-10856 (reporting on continuing reductions of toxic substances in products and emissions).

138. REACH, supra note 45 , at arts. 31-39.

139. Id. at arts. 118-19.

140. Id. at arts. $77(2)(\mathrm{e}), 119$.

141. EUROPEAN COMM'N, QUESTIONS AND ANSWERS ON REACH, supra note 95, at 26.

142. In addition, the EU will be considerably less receptive to claims of confidential business information. REACH, supra note 45, at arts. 118-119; see also EUROPEAN COMM'N, QUESTIONS AND ANSWERS ON REACH, supra note $95, \S 13.1$ (stating must affirmatively approve claims); DENISON, supra note 61 , at VIII-8-11.

143. Commission White Paper, supra note 2, at 7 ; e.g. REACH, supra note 45 , at preamble arts. 13 , 33.

144. REACH, supra note 45 , art. 25. "One substance, one registration" in effect permits the use of data in one company's registration of a chemical to be used in all registrations. By avoiding the duplicative registration of individual chemicals, REACH seeks to reduce the amount of animal testing required. 
volume chemicals, ${ }^{145}$ pre-registration and dossier review to determine whether animal testing can be avoided, acceptance of non-EU test results, discouraging repeated testing, and the widespread acceptance of non-vertebrate testing. ${ }^{146}$ In the debates over REACH, industry and animal rights groups both emphasized the uncertainties of animal tests as a surrogate for testing on humans, and they agreed on the desirability of finding alternatives. ${ }^{147}$ The upshot is a strong commitment in REACH to in vitro (non-animal) testing and the development of reliable quantitative chemical structure-activity (QSAR) analysis and in vitro testing as a substitute for traditional animal testing. By translating the results of non-animal testing to mammalian effects, QSARs aspire to be the cheap, "fast track option to deal with data gaps on chemicals," 148 and they do not require the use of animal models (at least, not after the initial effect and potency models have been determined). Animal testing is to be a last resort in all cases. ${ }^{149}$ To the extent that the mandate for non-animal testing results in faster, cheaper, and reliable assessment of chemicals, it is an idea that also holds general promise for improved chemicals regulation.

\section{SYNTHESIS: SHARED IDEAS AND TSCA REFORM}

Synthesis, in the Hegelian conception, is a new paradigm that grows out of the conflict of thesis and antithesis. Therefore, in seeking a synthesis of chemical regulatory regimes, especially a synthesis that could be implemented as reform of TSCA, it will be most promising to examine elements common to TSCA and REACH, correction of the worst failures of TSCA, and the most useful new ideas in REACH.

The time is right to develop such a synthesis. TSCA is clearly overdue for reform, as the litany of disappointments and criticisms in Part II demonstrates. The passage of REACH has produced an avalanche of concern in the United States about chemical regulation, because hundreds of American companies

145. Id. at art. 12.

146. These are specifically mentioned in all of the Annex lists of required testing, especially Annex. XI, which provides for waivers of testing. See id. at Annex XI.

147. European Comm'n, Scientific Comm. on Toxicity, Ecotoxicity \& the Envt, Opinion on the BUAV-ECEAE Report, "The Way Forward-Action to End Animal Toxicity Testing" (January 8, 2004), available at http://ec.europa.eu/health/ph_risk/committees/sct/documents/out217_en.pdf [hereinafter The Way Forward]. In the United States, animal testing has encountered some skepticism by courts reviewing agency action (e.g., Gulf South Insulation v. Consumer Product Safety Comm'n, 701 F.2d 1137,1147 (5th Cir. 1983)), and so acceptance of non-animal testing will probably take some time. See, e.g. U.S. GOV'T ACCOUNTABILITY OFFICE, supra note 64, at 11-15 (suggesting QSAR is not ready for prime time). EPA has in fact pioneered the use of QSAR techniques as part of its PMN review process, and the National Academy of Sciences recently reported that non-animal testing will become increasingly reliable and increasingly common. NATIONAL RESEARCH COUNCIL, supra note 51, at 3. And, to the extent that such methods tum out to be reliable, cheap, and fast, they will further the protective goals of chemical regulation.

148. Assessment of Additional Testing Needs, supra note 58, at 7.

149. Id. at art. 25(1). 
will need to learn how to comply to maintain important European markets ${ }^{150}$ and the chemical information that is generated in response to REACH will be available (more or less instantaneously) in the United States. Congress has begun to take a serious interest in REACH and its possible relation to TSCA reform, and environmental groups are creating pressure to do so. Efforts to adopt REACH-like statutes in the states, particularly a state like California, are likely to put pressure on Congress in 2009 to reform TSCA to avoid an inconsistent, piecemeal regulatory scheme in this country. ${ }^{151}$ Under these circumstances, TSCA reform, long overdue, is a realistic prospect.

\section{A. Plus ça change, plus c'est la même chose}

While REACH is the anti-TSCA in several important ways, the regulatory regimes actually have much in common. CEQ's 1971 Toxic Substances report perceptively identified the key challenges in regulating industrial chemicals, and the basic structure of TSCA represents an integrated, comprehensive approach. The European Union seeks to accomplish essentially the same goals with $\mathrm{REACH}$. Although REACH embodies a range of innovations-shifting the burden of proof, eliminating the distinction between new and existing chemicals, methodically addressing the "burden of the past," reducing reliance on non-animal testing, and so on-these mostly reflect efforts to shape different, and presumably more effective, techniques for accomplishing shared goals.

\section{Twin Goals of Environmental and Economic Health}

The fundamental objectives of both TSCA and REACH are protection of human health and the environment, and protection of the economic health of their respective chemical industries. ${ }^{152}$ As between the two, both also give nominal primacy to protecting health and the environmental protection. TSCA:

authority over chemical substances and mixtures should be exercised in such a manner as not to impede unduly or create unnecessary economic barriers to technological innovation while fulfilling the primary purpose of this chapter to assure that such innovation and commerce in such chemical substances and mixtures do not present an unreasonable risk of injury to health or the environment. ${ }^{153}$

Likewise, REACH:

The purpose of this Regulation is to ensure a high level of protection of human health and the environment, ... as well as the free circulation of

150. U.S. Commercial Service Website, U.S. Mission to the European Union, http:// www.buyusa.gov/europeanunion/reach.html (last visited November 7, 2008).

151. See Pat Rizzuto, Report Supplement: Toxic Substances: Preparation for REACH, State Legislation Likely to Consume Chemical Industry's Time, 39 ENVT. REP. (BNA) 185 (Jan. 18, 2008).

152. Commission White Paper, supra note 1, at 4.

153. TSCA § 2(b)(3), 15 U.S.C. 2601(b)(3) (2006) (emphasis added). 
substances on the internal market while enhancing competitiveness and innovation. ${ }^{154}$

REACH was jointly sponsored by the Enterprise and Industry and the Environment directorates general (DGs). DG Enterprise and Industry repeatedly emphasized the benefits to the chemical industry of maintaining confidence in chemicals and of spurring innovation. ${ }^{155}$

Each system balances one goal against the other. TSCA's "unreasonable risk" standard expressly takes into account economic and social factors. In $\mathrm{REACH}$, this balance is seen as an embodiment of "the overriding goal of sustainable development," to which the EU is committed. ${ }^{156}$ The balance struck between the goals is significantly different, primarily in that REACH is far less compromised by procedural complexity and strict judicial review. Nevertheless, both systems aim to shape (and, if possible, enhance) rather than eliminate the chemical industry.

\section{Chemicals as Chemicals}

Both TSCA and REACH chose to regulate chemicals themselves, rather than their presence in various environmental media, because media-based regulation requires greater complexity and would likely have unintended consequences that flow from fractured and overlapping authorities. TSCA addressed these concerns by regulating chemical substances and providing wide ranging control authorities to cover manufacture, use, and disposal. ${ }^{157}$ It also encouraged EPA to use TSCA to coordinate the activities of the mediaspecific federal statutes. ${ }^{158}$

Although of similar approach, REACH does not even discuss media-based approaches, probably because the idea of regulating chemicals as such was already well established in EU law. Europe also has a constitutional commitment that "environmental damage should as a priority be rectified at [its] source,"159 which clearly favors the chemical-specific approach. Of even greater immediate importance to the drafters of REACH was the need to harmonize and rationalize the many different $\mathrm{EU}$ regulations and directives and their interpretations in all of the member states into "a single coherent system." 160 The regulation of chemicals as such advances all of these goals and represents a basic commonality between the statutes.

154. REACH, supra note 45, at art. 1(1) (emphasis added).

155. See EUROPEAN COMM'N, QUESTIONS AND ANSWERS ON REACH, supra note 95, § 13.4.

156. Commission White Paper, supra note 1, at 4 (emphasis in original).

157. TSCA $\S 6(a)$.

158. Id. $\S 9(\mathrm{~b})$; see also Applegate, Bridging the Data Gap, supra note 20, at 330-32.

159. Treaty of European Union, supra note 122, at art. 174(2).

160. Commission White Paper, supra note 1 , at 16. 


\section{Prevention}

When TSCA was enacted in 1976, the idea of prevention as a complement to the tort system was perhaps not yet firmly established, and it was necessary to emphasize it. ${ }^{161}$ Thirty years later, the European Commission's White Paper hardly needed to argue the point: "decisionmaking must be based on precaution to prevent damage to human health and the environment."162 By 2001, the debate had moved beyond prevention to precaution. For some observers, the precautionary principle had marked a fundamental shift from avoiding known risks to anticipating suspected ones. ${ }^{163}$ The European Commission resisted the most aggressive normative understandings of the precautionary principle and insisted on a protective and anticipatory, but still strongly science-based and cost-sensitive, approach. ${ }^{164}$ REACH follows the Commission's interpretation of the precautionary principle. ${ }^{165}$ For instance, as we have seen, the authorization and restriction procedures both involve risk-cost-benefit balancing. The REACH approach to prevention is intended to be more anticipatory than TSCA in the sense of being expressly less demanding of scientific certainty in advance of regulation (i.e., adopting the precautionary principle), but both fundamentally pursue the objective of preventing harm with a risk-benefit measure of the proper level of control.

\section{The Data Gap}

Concern over the lack of chemical knowledge is perhaps the most striking commonality of the two legislative regimes. It was a primary concern in Toxic Substances in 1971, and TSCA provided a range of devices to fill the data gap. The developers of REACH also sponsored studies of the data gap decades later, which confirmed earlier findings of a serious problem. ${ }^{166}$ However, they went further and concluded that the data gap could not be filled by the TSCA approach. The Commission asserted, "In fact, not one country has yet been successful in overcoming the huge gap in knowledge of substances." 167 While REACH adopts a different data-acquisition strategy from TSCA, it has the same basic objective of filling the data gap. Neither piece of legislation addresses the problem at a fundamental level by seeking to "bridge" the gap by

161. US CEQ, supra note 2, at 20-21.

162. Commission White Paper, supra note 1, at 5 (emphasis added).

163. Applegate, The Taming of the Precautionary Principle, supra note 123, at 17-20.

164. Communication from the Commission on the Precautionary Principle, supra note 123, at 3-5, $14,18-21$.

165. Commission Proposal, supra note 1, at 19; Heyvaert, Guidance without Constraint, supra note 117 , at 51 .

166. Assessment of Additional Testing Needs, supra note 58, at 5 (citing earlier studies); DENISON, supra note 61 , at VIII-8-11.

167. Commission White Paper, supra note 1, at 5. 
adopting regulatory standards that would require less information to operate. ${ }^{168}$ Instead, like TSCA, REACH is committed to an information-intensive approach and provides mechanisms that are designed to generate comprehensive data on chemicals for use by regulators.

\section{Risk, Proportionality, and Cost}

Both TSCA and REACH are based on the evaluation of probabilistic risk. Rather than seeking simply to eliminate any chemical which might pose a risk, TSCA and REACH instead evaluate the acceptability of risk of exposure as weighted by the harm that would result from that toxic exposure. Both adopt a probabilistic meaning of risk and abandon the bi-modal, safe-unsafe paradigm of the Delaney Clause, discussed above. Although TSCA itself does not define it, "risk" in the statute has uniformly been interpreted as a probabilistic statement of the product of toxicity and exposure, with an acceptable level lying at a point above zero. ${ }^{169} \mathrm{REACH}$, too, relies on risk as the basis for regulation. Intrinsic properties (such as carcinogenicity, mutagenicity, and reproductive toxicity (CMR)), trigger data and evaluation requirements; however, regulatory controls are ultimately based on intrinsic characteristics and exposure levels, that is, on probabilistic risk. Both types of information are required in the base set of data for registration, ${ }^{170}$ in the chemical safety report, ${ }^{171}$ and in the terms of control for authorization. ${ }^{172}$ Exposure levels are a key element of control in restrictions. ${ }^{173}$ Here again, the Commission's interpretation of the precautionary principle lends support, by placing the principle firmly in the context of risk management. ${ }^{174}$

The use of probabilistic risk and the commitment to proportionality beg the question how to fix the point on the incremental scale of risk at which regulatory action is triggered. ${ }^{175}$ Both regulatory schemes seek to incorporate cost considerations in making the determination of where and how to impose controls. The "unreasonable" terminology in TSCA is notably unspecific, and intentionally so, ${ }^{176}$ but it is clear that EPA must consider cost as well as risk in its determinations of "unreasonable risk." 177 The establishment of any

168. Technology-based standards, for example, demand relatively little chemical information, while risk-based standards tend to require a great deal. Risk-based TSCA, in contrast, requires EPA to consider a wide array of information, including alternatives, and it backs this up with specific required findings and aggressive judicial review. Applegate, Bridging the Data Gap, supra note 20, at 1396-98; Applegate \& Fischman, supra note 32, at 402-04.

169. H.R. REP. No. 94-1341, at 14 (1976).

170. REACH, supra note 45 , at art. 10(a), Annex VI

171. Id. at art. 14.

172. Id. at art. 60(2).

173. Id. at arts. $69-70$.

174. Communication from the Commission on the Precautionary Principle, supra note 123, at 3 .

175. Applegate, Perils, supra note 24, at 271-77.

176. H.R. REP. No. 94-1341, at 13-14 (1976).

177. S. REP. NO. 94-698, at 13,16,20 (1976); H.R. REP. NO. 94-1341, at 13-14, 35 (1976). 
regulatory control must include "a statement with respect to" the human and environmental risks of the chemical, the benefits and available substitutes for the chemical, and "the reasonably ascertainable economic consequences of the rule." 178

REACH also incorporates cost considerations. While the data requirements of registration do not include the cost of regulation, though information concerning uses is required, ${ }^{179}$ cost comes into play at the authorization phase. Manufacture or import is presumptively banned based on key intrinsic properties, but then it may be authorized for particular uses that either can be adequately controlled ${ }^{180}$ or, if they cannot (and CMRs by definition cannot), then justified if benefits of the chemical outweigh its environmental costs. ${ }^{181}$ This, too, is in keeping with the Treaty on European Union $^{182}$ and the Communication on the Precautionary Principle, ${ }^{183}$ both of which mandate the consideration of cost in imposing environmental restrictions. Restrictions require the opinion of the Committee for SocioEconomic Analysis, ${ }^{184}$ and the Commission must justify a rejection of its recommendations. 185

Risk in the probabilistic sense, and the consideration of cost and other non-health factors, serve to ensure that the regulator's response to the risk is proportionate to the scale of the problem identified. To underscore this point, TSCA's regulatory measures are to be the "least burdensome" needed to address the problem, ${ }^{186}$ and testing must be "necessary" to obtain information that is "relevant" to regulatory decisions. ${ }^{187}$ The restrictions must fit the risk, in other words. Proportionality is also a basic principle of European law. ${ }^{188}$ The Commission made proportionality a major guideline for applying the precautionary principle, ${ }^{189}$ and proportionality permeates $\mathrm{REACH}$, from the amount of data to be provided in the registration phase ${ }^{190}$ to the nature of the restrictions applied to VHC chemicals. Although they differ substantially in the balance that they strike, both REACH and TSCA, accept some level of risk

178. TSCA § 6(c)(1), 15 U.S.C. § 2605(c)(1) (2006)

179. REACH, supra note 45 , at art. 10 (a).

180. "PBTs [persistent, bioaccumulative, or toxic], $\mathrm{VPvBs}$ [very persistent or very bioaccumulative], and those CMR [carcinogenic, mutagenic, or reproductively toxic] substances for which a safe level cannot be defined, cannot be authorized based on adequate control of risk." REACH IN BRIEF, supra note 94 , § 2.7.

181. REACH, supra note 45 , at arts. $60(4), 64(4)(b)$.

182. Treaty of European Union, supra note 122, at art. 174(3).

183. Communication from the Commission on the Precautionary Principle, supra note 123, at 1920.

184. REACH, supra note 45 , at arts. $68(1), 71$.

185. Id. at art. 73(1).

186. TSCA § 6(a), 15 U.S.C. $\S 2605(a)$ (2006).

187. Id. $\S 4(\mathrm{a})$.

188. Paul Craig \& Gráinne de Búrca, eu law: Text, Cases, and Materials 349-57 (2d. ed. 1998).

189. Communication from the Commission on the Precautionary Principle, supra note 123 , at 18.

190. Commission White Paper, supra note 1, at 3. 
from chemicals (as noted, neither envisions fundamental restructuring or replacement of the chemical industry), and so they adopt regulatory standards of probabilistic risk moderated by considerations of proportionality and cost.

\section{Priorities}

The acceptance of a spectrum of risk means that not all hazards are of equal regulatory concern, which in turn counsels the wisdom (if not the inevitability) of setting priorities. It is a reflection of both aspiration and inexperience that early U.S. environmental statutes assumed that environmental problems could be resolved once and for all within a fairly short period of time. TSCA was perhaps ahead of its time in recognizing that its look-back device for generating toxicological information, the section 4 test rule, would take time to implement fully. The statute established an Interagency Testing Committee (ITC) to create and update a priority list for testing existing chemicals. ${ }^{191}$ TSCA gives both flexibility (a very wide range of relevant considerations) and direction (carcinogens, mutagens, and teratogens are priorities) to the committee. However, while a priority list was developed and is regularly updated, it is a short list ${ }^{192}$ (limited to fifty) by comparison to the thousands of chemicals of regulatory concern. In any event, the testing deadlines - and indeed the list itself - have been essentially ignored.

$\mathrm{REACH}$, on the other hand, proceeding from a burden on the manufacturer to obtain permission to sell or to continue to sell, has a far more robust priority setting mechanism. "Prioritisation is built into the system throughout." 193 Since eliminating the data gap for existing chemicals is a central objective of $\mathrm{REACH}$, the legislation provides express guidance for a "step by step process to address the "burden of the past." 194 REACH incorporates a more sophisticated scheme for setting priorities based on hazard or exposure. ${ }^{195}$ For priority based on hazardous characteristics (that is, intrinsic properties), REACH goes beyond CMR (which is in the TSCA section 4(e) priorities) or HPV (the TSCA "B-Policy"), to focus in addition on persistence and bioaccumulation. ${ }^{196} \mathrm{As}$ in the other aspects of the regulatory scheme that we have examined, REACH seeks to implement more effective regulation, rather than impose a radically different approach.

191. TSCA $\S 4(\mathrm{e})$.

192. Id. $\S 4(\mathrm{e})(\mathrm{I})(\mathrm{A})$.

193. EUROPEAN COMM'N, QUESTIONS AND ANSWERS ON REACH, supra note 95, $\S 2.5 .2$.

194. Commission White Paper, supra note 1 , at 7.

195. EUROPEAN COMM'N, QUESTIONS AND ANSWERS ON REACH, supra note 95, § 2.5.2.

196. Another parallel is that both the CMR factors and production volume are testing priorities under TSCA. TSCA $\S 4(a)(1)(B), 15$ U.S.C. $\S 2603$ (a)(1)(B) (2006) (the so-called B-Policy for testing high volume chemicals) and $\S 4(\mathrm{e})$ (criteria for the Interagency Testing Committee). 


\section{Comprehensive Rationality}

Finally, both TSCA and REACH adopt the general approach to regulation that Professor McGarity calls "comprehensive analytical rationality."197 This approach reaches decisions by gathering and systematically analyzing all of the relevant information about a given problem and its potential, with the objective of implementing the optimal regulatory response. Comprehensive rationality includes and goes beyond the idea of synopticism. It does not merely seek to address all aspects of a problem, but also to base decisions on analytical tools that emphasize quantitative information and the search for a theoretically optimized response. ${ }^{198}$

The aspiration to comprehensiveness is inherently data-hungry. More, it implies that the data should be quantitative where possible in order to permit formal analysis using tools like quantitative risk assessment and cost-benefit analysis. The comprehensive aspirations of REACH and TSCA are evident in the importance that each places on gathering information concerning chemicals. The hazards are defined in terms of risk, itself a complex and multi-faceted concept, and the acceptable level of risk is determined through an open-ended analysis of benefits, costs, technologies, substitutes, and alternative approaches. While TSCA does not mandate particular regulatory tools, REACH in effect does by requiring the involvement in later stages of the process of a Committee for Risk Assessment and a Committee for Socio-economic Analysis. 199

Both TSCA and REACH share a fundamental regulatory commitment to science-based regulation. It is not coincidental that the above committees take on the responsibilities of the Commission's Scientific Committees in this area. ${ }^{200}$ While this may seem almost too obvious to mention, the commitment has a history and important consequences. The history, very briefly, is that science was responsible for many of the insights that brought environmental law into being. For chemical regulation, Rachel Carson's work serves as a good starting point. The novel and persuasive feature of Silent Spring was Carson's use of science to demonstrate the extent of the problem of pesticides. ${ }^{201}$ Since then, we have relied on science to reveal problems, and science has become the central justification for regulatory actions that are expensive or otherwise unpopular. ${ }^{202}$

Perversely, in view of this history, the science-based approach in TSCA has been used to justify aggressive interpretation of the evidentiary and

197. See Thomas O. MCGarity, ReinVenting Rationality: The Role Of Regulatory ANALYSIS IN THE FEDERAL BUREAUCRACY (1991).

198. Id.

199. REACH, supra note 45 , at art. 64 .

200. REACH, supra note 45, at Preamble (102).

201. RACHEL CARSON, SILENT SPRING (1962).

202. See Wendy E. Wagner, The Science Charade in Toxic Risk Regulation, 95 ColuM. L. REV. 1613, 1651-1654 (1995) (suggesting that non-scientific considerations are often at work in regulatory actions, despite the nominal reliance on scientific rationales). 
procedural requirements of the statute to advance an anti-regulatory agenda. In the spirit of the "sound science" movement, opponents of regulation have successfully demanded that regulatory action be withheld without clear, nearly incontrovertible scientific demonstration of the nature and extent of environmental harm. ${ }^{203}$ In Corrosion Proof Fittings, the case that brought nonvoluntary TSCA programs to a virtual standstill, the court was highly critical of the quality and definitiveness of EPA's one hundred thousand-page scientific record on the effects of asbestos. ${ }^{204}$ In view of the findings and substantial evidence provisions of TSCA, the record was deemed insufficient to support the restrictions that EPA had imposed. ${ }^{205}$

In $\mathrm{REACH}$, the European Union responds to the debate over the role of science. The precautionary principle, of course, seeks to avoid obstructionist use of "sound science" by authorizing regulation in advance of certainty. Indeed, the standard formulation of the principle is couched as a rhetorical counter-move ("shall not be used as a reason"), ${ }^{206}$ rather than an affirmative substantive command. On the other hand, entities like the World Trade Organization (WTO), with a greater stake in economic activity than in environmental protection, insist that regulatory restrictions be based on scientific information. ${ }^{207}$ The European Commission, seeking to reconcile European commitments to strong environmental protection and to free trade under the auspices of the WTO, incorporates precaution into a science-based risk assessment framework, and limits its use to the specific situation of residual uncertainties. ${ }^{208}$ While it adopts a reversed burden of proof and other information-generating devices, REACH ultimately adopts a filling approach to the data gap and requires a "sound scientific basis" for restrictions on chemicals. ${ }^{209}$

In all of these respects, REACH and TSCA bear important and fundamental similarities in their approaches to chemicals regulation. Both balance protection of human health and promotion of the chemical industry, they regulate chemicals as such to supplement the media-based statutes, they seek to prevent toxic harm before it occurs, they regulate on the basis of a risk characterized by less-than-absolute safety and modified by cost and other nonhealth considerations, they are information-intensive in that they aspire to fill

203. See Thomas O. McGarity, Our Science is Sound Science and Their Science is Junk Science: Science-Based Strategies for Avoiding Accountability and Responsibility for Risk-Producing Products and Activities, 52 KAN. L. REV. 897, 897-901, 904-908 (2004).

204. Corrosion Proof Fittings v. EPA, 947 F.2d 1201, 1229-30 (5th Cir. 1991).

205. Id.

206. Rio Declaration, supra note 127 , at 115.

207. Agreement on the Application of Sanitary and Phytosanitary Measures, Final Act Embodying the Results of the Uruguay Round of Multilateral Trade Negotiations, Apr. 15, 1994, available at http://www.wto.org/english/docs_e/legal_e/15-sps.pdf.

208. Communication from the Commission on the Precautionary Principle, supra note 123, at 13$15,20-21$.

209. REACH, supra note 45, at arts. 69-73; see also Commission Proposal, supra note 1, at 16, 37. 
the data gap (albeit in different ways), and each is committed to a comprehensive, analytical approach to regulation.

\section{B. Practical Principles for TSCA Reform}

Taken together, the areas of commonality between TSCA and REACH, the widely acknowledged failures of TSCA, and the regulatory innovations in $\mathrm{REACH}$, suggest four interrelated principles for improvement of chemicals regulation:

1. Chemical regulation should be preventive and its restrictions proportionate to the risk presented;

2. Chemical regulation should aim for progressive improvement in chemical safety;

3. Regulation should be based on all currently available information, and lack of full information should not be a barrier to regulatory action;

4. The regulatory process should be as transparent and as simple as possible.

It bears emphasis that these principles are not necessarily the principles that one would adopt if writing on a blank slate. They represent only a modest proposal and not a paradigm shift in chemical regulation. Rather, the principles represent a synthesis between the TSCA and REACH regulatory approaches; therefore, they offer the best prospect of adoption when TSCA is revised in the near future.

\section{Prevention and Proportion}

Much of the nominal approach of TSCA to prevention and proportion would be retained as an effective way to regulate chemicals. Substantively, chemicals regulation should be preventive and its restrictions proportionate to the risk presented. Prevention of harm before it occurs is the principal justification for governmental regulation of chemicals. It has both the normative underpinning of preventing unconsented harm and the utilitarian goal of cost-effective environmental management-prevention being cheaper than repair. In an industrial society, perfect safety is an unattainable, if not incoherent, goal; therefore, regulatory restrictions need to be related-though not precisely calibrated-to the prospective harm. This principle suggests the following corollaries:

Risk-based regulation. TSCA already establishes risk-based regulation which incorporates both prevention and proportion. Risk-based regulation is preventive, because it addresses probabilities of harm, rather than actual harm. Risk-based regulation also facilitates proportionate responses, because risk can be (and usually is) understood to be scaled rather than bi-modal, measured by the likelihood of harm of a particular magnitude.

Chemical-based approach. For the reasons detailed above, regulating chemicals as such-that is, at the beginning rather than the end of their life 
cycle-is widely acknowledged to be the most efficient and effective way to achieve a preventive approach.

Cost-sensitive. Acceptance of a greater-than-zero residual risk from chemicals, which risk and proportionality both imply, ${ }^{210}$ necessitates the establishment of some criteria for determining the acceptable level of risk between zero and one hundred percent. Both TSCA and REACH take cost into account in making this determination. However, even in TSCA, where costs are more heavily weighted and the burden of justification is placed on the agency, cost does not necessarily determine outcomes. Moreover, neither demands a formal, quantitative cost-benefit justification for regulatory action. ${ }^{211}$ Regulatory action should be sensitive to costs rather than determined by them.

Although TSCA is already grounded in these principles, reform should permit such analysis to go forward on the basis of actually available information. For example, the approach of Corrosion Proof Fittings, which raised a nearly insurmountable evidentiary bar to substantial regulation, makes a balancing analysis nearly impossible if estimates of risk are in effect not permitted. $^{212}$ Ultimately, cost should be a boundary factor at the outer limits of acceptable levels of risk. That is, it should function more like it does in a feasibility analysis, to limit only the most damagingly expensive impositions.

\section{Progressive Improvement}

Chemical regulation should aim for progressive improvement in chemical safety. Neither TSCA nor REACH adopts the goal of a chemical-free economy, but rather the control of dangerous chemicals before they cause harm to human health or the environment. "The European Union is aiming to achieve that, by 2020 , chemicals are produced and used in ways that lead to minimization of significant adverse effects on human health and the environment." 213 A commitment to progressive improvement is, if not particularly encouraged by, at least consistent with TSCA. For example, the ITC process was clearly intended to identify the most problematic chemicals for further testing and subsequent restriction. As Professor Driesen has argued, given the difficulty of determining the precise costs and benefits of environmental harm, it makes more sense to point potentially harmful activities in the right direction than to try to define a static, optimal norm. ${ }^{214}$

210. Conversely, one could say that risk and proportionality reject the hazard model of a bi-modal choice between safe and unsafe.

211. H.R. REP. No. 94-1679, at 9, 13-14 (1976) (stating that consideration of cost does not imply "any cost-benefit justification").

212. See Corrosion Proof Fittings v. EPA, 947 F.2d 1201, 1229-30 (5th Cir. 1991).

213. REACH, supra note 45, at Preamble (4). REACH describes this objective as sustainable development because it tries to bridge economic growth and environmental protection. See Commission White Paper, supra note 1 , at 4.

214. See generally David M. Driesen, The Economic Dynamics of Environmental Law (2003). 
Identify and eliminate the worst chemicals. TSCA can especially benefit from the incorporation of more sophisticated and robust priority-setting mechanisms. Because regulatory resources are limited, the failure to establish deliberate priorities among the thousands of chemicals in commerce paralyzes regulatory action. The first step of progressive improvement, therefore, is to take action against the chemicals whose release into the environment presents irreversible harm because of their toxicity or persistence. So that priority setting does not become an end in itself, priority setting based on proxies like production volume, inherent characteristics, or persistence in the environment-triage, in effect-is sensible, if not necessary. The Canadian Environmental Protection Act is an excellent model. Focusing on relative rather than absolute hazard, it has made tremendous progress in a relatively short time. 215

Learn how to live safely with what remains. The next step in progressively preventing harm is to learn how to live safely with what remains. The "safety case" is a familiar concept in Europe, but is seldom used in the United States. It refers to a portfolio of information that characterizes a chemical and its uses, and that demonstrates, using appropriate information and assumptions, how it can be used safely through its life cycle. The chemical safety report required by $\mathrm{REACH}^{216}$ is essentially a safety case, especially since it includes appropriate use restrictions, as well as risk information. While the safety case concept does not presuppose any particular definition of what is acceptably safe, European environmental policy requires a "high level of protection."217 Although "high level of protection" is a fair description of most U.S. statutory standards as well, TSCA currently does a poor job of demonstrating comprehensive safety. Reform of TSCA should provide some mechanism for developing substantitive use requirements that would reduce the risks from use as much as is practicable.

Strong incentives for finding safer substitutes. Innovation is essential to the continued competitiveness of the chemical industry. By directing innovation toward safer alternatives, an economically healthy chemical industry can contribute importantly to safety. In addition to the techniques deployed in $\mathrm{REACH}$, a direct way to create this incentive is to require that the justification for the use of a chemical include an analysis of the chemical in the context of its substitutes and their respective life cycles. ${ }^{218}$ The Massachusetts

215. Government of Canada, Chemicals Management Plan, http://www.chemicalsubstances chimiques.gc.ca/plan/index_e.html (last visited Oct 16, 2008); see also DENISON, supra note 61, at I-45; Peter Menyasz, Canada Issues List of Priority Chemicals, Calls on Industry to Report Certain Emissions, 31 INTL. ENVT. REP. (BNA) 203 (March 5, 2008) (describing progress to date and ongoing efforts).

216. REACH, supra note 45 , at art. 14.

217. Treaty of European Union, supra note 122, at 174(2).

218. Lars Koch \& Nicholas A. Ashford, Rethinking the Role of Information in Chemicals Policy: Implications for TSCA and REACH, 14 J. CLEANER PRODUCTION 31, 37 (2006). 
Toxics Use Reduction Act, for example, requires the manufacturers and users of toxic chemicals to generate use reduction plans. ${ }^{219}$ While the plans need neither be followed nor publicly disclosed, the investment in the development of the plans is expected to encourage their implementation.

Alongside mechanisms for minimizing the risks from chemicals, TSCA should require consideration of reductions in the volume of chemicals produced and sold, in addition to restrictions on the permitted uses, to encourage the search for substitutes. Both amounts and uses could be ratcheted down over time.

Further progress. Such progressive incentives would also embody a principle of requiring further progress toward safety as technology and practices improve. The idea of progressive substitution of safer chemicals can be extended to a continuing obligation to seize opportunities for greater chemical safety. This is expressed, for example, in the limited lives of REACH authorizations, ${ }^{20}$ in contrast to TSCA, which does not require subsequent reauthorization except for "new" uses. More importantly, it is expressed in the $\mathrm{REACH}$ authorization requirement that "[n]otwithstanding any conditions of an authorization, the holder shall ensure that the exposure is reduced to as low a level as is technically and practically possible."221 The Communication on the Precautionary Principle also suggested an ALARA ("as low as reasonably achievable") standard 222 as a way to deal with uncertainty. ALARA is not a widely used concept in U.S. environmental law; however, it is a central-and arguably quite successful-element of the somewhat esoteric area of nuclear safety, ${ }^{223}$ and it could be more widely deployed.

\section{Precaution}

TSCA and REACH clearly make the filling rather than the bridging choice for chemical data, in that they require the systematic evaluation of chemicals on a case-by-case basis. An inherently data-intensive and time-consuming approach, it must be tempered with precaution to avoid regulatory paralysis in the face of incomplete or uncertain information. Regulation should be based on all actually available information, and the lack of full information should not be a barrier to preventive action. As reformers of TSCA consider options, it is critical that they not respond to the data gap by retreating from a protective standard.

Consider all relevant, available information. Regulation should not be based on deliberate ignorance, and regulators should be able to consider the

219. See supra note 135 .

220. REACH, supra note 45 , at art. $60(8)-(9)$.

221. Id. at art. $60(10)$.

222. Communication from the Commission on the Precautionary Principle, supra note 123, at 15.

223. United States Nuclear Regulatory Commission, Standards for Protection Against Radiation, 10 C.F.R. $\S \S 20.1003,20.1101$ (2008). 
range of relevant data, including scientific, technologic, economic, and social information, in reaching decisions. However, consistent with precaution, some points in the regulatory process (for example, data gathering) must be able to proceed on the basis of limited data. TSCA reform should remove the current incentives for ignorance.

Generate information for existing and new chemicals. The demand for and supply of information is a central aspect of any chemical regulation scheme. Having created a demand for information, a regulatory system needs to have mechanisms in place to ensure that the information is supplied. ${ }^{224}$ As we have seen, REACH - with the advantage of thirty additional years of experience with chemical regulation in Europe and the U.S. - is more urgently focused on information needs than TSCA was. In addition, to the extent that European efforts to obtain reliable toxicological data without animal testing are successful, they could result in a faster and cheaper regulatory process. Whether TSCA reform requires manufacturers to supply such information or authorizes and funds EPA to conduct the necessary research itself, TSCA must provide more effective means for generating the needed information.

Follow a precautionary approach. One of the central realities of chemical regulation is that the needed information is not now available, nor is it likely to be available in the immediate future. Therefore, if TSCA is to be truly preventive, TSCA reform must incorporate provisions that expressly permit EPA to act in advance of full information. The provisions of REACH "are underpinned by the precautionary principle"225; it is a basic requirement of all European environmental law, and the idea of precautionary action has a long history in U.S. environmental law. ${ }^{226}$ For these purposes, the precautionary principle is not (and was never intended to be) a rule that gives specific direction in particular cases. It is, rather, a general statement of the relationship, especially as regards timing, between the exercise of governmental regulatory authority and available information. ${ }^{227}$ As such, it is an essential baseline element of an information-dependent regulatory system.

Iteration. Some more recent versions of the precautionary principle require that decisions based on less than full information be revisited as more information becomes available. This requirement is designed to reconcile science-based regulation with preventive regulation, and the idea can be broadened to encompass the obvious logic of revisiting prior decisions on the basis of significant new information. Professor Doremus melds these aspects of precaution with other recent scholarship on regulatory use of new information to suggest that precaution works best in a regulatory system that is capable of learning; that is, adjusting in response either to previously unknown or

224. See generally Applegate, Bridging the Data Gap, supra note 20.

225. REACH, supra note 45 , at art. 1(3).

226. John S. Applegate, The Precautionary Preference: An American Perspective on the Precautionary Principe, 6 HUM. \& ECOLOGICAL RISK ASSESSMENT 413, 420-29 (2000).

227. See Fisher, supra note 124, at 20-23. 
uncertain information, or to observation of the response to regulatory action. ${ }^{228}$ An iterative approach also supports progressive improvement of chemical safety.

Taken together, the principles of precaution and iterative learning in the regulatory scheme suggest a fundamental reworking of the structure of TSCA. At least in the context of the registration of chemicals, provision should be made for both initial restriction and periodic revisiting of registrations. However, given the procedural bulkiness of TSCA, such intensive and repeated efforts would be unworkable without making the regulatory apparatus of TSCA far more nimble than it is today.

\section{Transparency and Simplicity}

Procedurally, the regulatory system should be transparent and simple, or at least as simple as basic procedural fairness and informed deliberation allow. Some of these considerations flow from the principles above, but they are also grounded in a wider vision of participation and inclusion of the public that is exposed to the harms that result from misuse of chemicals.

Provide the public with full chemical safety information. As we have seen, providing the public with full information about chemical safety and management permits individual decision making and collective (i.e., political or legal) action. Transparency concerning relevant information is also essential to meaningful public participation in the administrative process. The internet has created the potential for widespread public access to chemical safety information in a number of forms and at different levels of technical detail. Regulatory systems should not only require the production of relevant information, but also organize it and make it available in broadly usable formats.

Limit procedural complexity. Procedural complexity works against the general principles of a protective regulatory scheme. An iterative, learning system that seeks progressive improvement of chemical safety needs to be nimble in responding to new hazards and new information about existing areas of concern. The informal rulemaking procedure in U.S. administrative law ${ }^{229}$ was designed to achieve this flexibility, but it has "ossified" over time, becoming more rigid and complex. ${ }^{230}$ TSCA is perhaps the ne plus ultra of ossification. The extraordinary procedural elaboration deployed by TSCA protects the no-regulation status quo, ${ }^{231}$ but it also slows responses to any new

228. Holly Doremus, Precaution, Science, and Learning While Doing in Natural Resource Management, 82 WASH. L. REV. 547 (2007).

229. Administrative Procedure Act (APA), 5 U.S.C. $\S 553$ (2006).

230. Thomas O. McGarity, Some Thoughts on "Deossifying" the Rulemaking Process, 41 DUKE L.J. 1385, 1385-85 (1992) (quoting E. Donald Elliott).

231. Daniel B. Rodriquez \& Barry R. Weingast, The Positive Political Theory of Legislative History: New Perspectives on the 1964 Civil Rights Act and Its Interpretation, 151 U. PA. L. REV. 1417, $1444-45$ (2003). 
information. Some procedural complexity is inevitable in achieving a truly participatory system and, especially in the case of the EU, to recognizing the relationship between the Union and its Member States. Nevertheless, procedural elaboration, including aggressive judicial review, should be avoided. Although in many instances regulatory actions may restrict chemical use in the initial stages as currently unrestricted chemicals face precautionary restrictions, with time the regulated industries would also benefit from rapid relaxation of such restrictions should subsequent information suggest restrictions are not necessary.

\section{CONCLUSION: CHEMICAL REGULATION AND GLOBALIZATION}

The premise of the comparative approach of this Article is that the chemical regulation systems of the European Union and the United States are well known to each other, that they have lessons for each other, and that they have an impact on each other. Relationships between national legal systems are not new, of course, but the intensity and practically instantaneous nature of today's relationships are. In this sense, the relationship of TSCA and REACH exemplifies the phenomenon of globalization. Globalization is distinct from the traditional international legal order in that it involves transnational impacts in informal, non-hierarchical ways. ${ }^{232}$ International law in the strict sense of the law of nations has very limited domestic application. With globalization, the laws or norms of one state affect actors in other states, not necessarily directly, but because many actors have a global existence (for example, multinational corporations) and find it necessary or valuable to follow the laws of multiple states. Pollution and products travel across borders, bringing their hazards with them. Likewise, states in their domestic lawmaking react to each other through direct observation and informal discussion, more than through formal agreements in an overarching treaty.

Chemical manufacturing and distribution is truly a global industry. Production is dominated by several multinational corporations, many of whose names are familiar, with facilities and markets all over the world. Hundreds of other companies export and import smaller amounts across the globe. For both the United States and Europe, chemicals are major export products and include substantial exports to each other. ${ }^{233}$ As a result, many chemical manufacturers and distributors, especially the larger ones, are subject to both TSCA and REACH. Efficiency, if nothing else, will demand that the chemical industry adopt practices that comply with both systems. Professor Wirth calls this the "California effect" (California is such a large market that its requirements often

232. Jost Delbrück, Globalization of Law, Politics, and Markets-Implications for Domestic LawA European Perspective, 1 IND. J. Global LeGal StUd. 9, 10-1 1 (1993).

233. Commission White Paper, supra note 1, at 4; see also American Chemistry Council, Did You Know?, http://www.americanchemistry.com/s_acc/sec_didyouknow.asp?CID=198\&DID=524 (last visited October 16, 2008). 
dictate behavior in other states) in his study of the impact that REACH has had and will have on U.S. chemicals regulation. ${ }^{234}$

It is no surprise, therefore, that U.S. chemical manufacturers are looking with great interest at REACH's demands. They will have to meet those demands if they are to maintain and expand markets in Europe. ${ }^{235}$ The trade press is full of advice in interviews, seminars, and papers, and the U.S. Department of Commerce issues regular advisories and tutorials about compliance. ${ }^{236}$ Moreover, to implement REACH, U.S. manufacturers and European regulators will undoubtedly (indeed, already do) rely heavily on data generated for TSCA and other mandatory and voluntary U.S. programs, such as the HPV Challenge. For its part, the European Chemicals Agency sees an opportunity to create a global regulatory community. It already works closely with U.S. and Canadian authorities, and it hopes to establish a "world standard' for chemicals assessment and management."237

Even more fundamentally, the strong commitment to transparency in $\mathrm{REACH}$, with the internet as the preferred means of presenting that information, will result in data generated on the east side of the Atlantic being more or less instantly available on the west side (and anywhere else) to virtually anyone who is interested. Indeed, the Organisation for Economic Cooperation and Development (OECD) has already created a website called eChemPortal that "provides free public access to information on chemical properties and direct links to collections of information prepared for government chemical review programmes at national, regional, and international levels." 238 And this new knowledge, of course, will be the basis for demands on regulators and other legal action on both sides of the Atlantic.

TSCA was proposed in 1971 and enacted in 1976. It has many strengths, but it also suffers from serious flaws. It has been ill-used in many ways by the courts and others, and it has devolved into little more than a forum for voluntary programs. TSCA is overdue for reform. The REACH approach, on

234. David A. Wirth, The EU's New Impact on U.S. Environmental Regulation, 31:2 Fletcher Forum of World Affairs 91, 100-106 (2007).

235. The US government and US industry conducted an unprecedented lobbying effort in Europe to derail or weaken REACH as it was going through the legislative process. GREENPEACE, TOXIC LOBBY: HOW THE CHEMICALS INDUSTRY Is TRYING TO KILL REACH 16 (May 2006), available at http://www.greenpeace.org/toxiclobby. See also SCHAPIRO \& GLICKSMAN, supra note 26, at 143-49. See also FRANK ACKERMAN, POISONED FOR PENNIES: THE ECONOMICS OF TOXICS AND PRECAUTION 217-26 (2008) (describing the analysis that U.S. chemical companies will undertake in deciding whether to continue to export to Europe).

236. See, e.g., U.S. Mission to the European Union, The Latest on REACH, http:// www. buyusa.gov/europeanunion/reach.html (last visited Nov. 29, 2008).

237. Stephen Gardner, New European Chemicals Head Outlines REACH Implementation Priorities, 30 INTL. ENVT. REP. (BNA) 931 (Nov. 28, 2007). See also SCHAPIRO \& GLICKSMAN, supra note 26 , at 156-58 (describing the pressure on U.S. chemical producers to conform to REACH).

238. Organization for Economic Co-operation and Development, eChemPortal, The Global Portal to Information of Chemical Substances, http://webnet3.oecd.org/echemportal/Contents.aspx? ContentName=Portalinfo (last visited October 13, 2008). 
the other hand, was conceived in 2001 with the TSCA experience very much in mind. And now, to complete the circle, TSCA is being reexamined by a newly receptive Congress and President. It is hoped that Congress will look to $\mathrm{REACH}$ for ideas, and that it can find in TSCA and REACH a synthesis of general principles and specific techniques that will assist it promptly to revise TSCA to be the effective protector of human health and the environment that was envisioned over three decades ago.

We welcome responses to this Article. If you are Interested in submitting a response for our online companion journal, Ecology Law Currents, please contact ecologylawcurrents@ boalt.org. Responses to articles may be viewed at our website, http://www.boalt.org/elq. 
